\title{
Testing and numerical modelling of lean duplex stainless steel hollow section columns
}

\author{
M. Theofanous and L. Gardner
}

\begin{abstract}
Stainless steels are employed in a wide range of structural applications. The austenitic grades, particularly EN 1.4301 and EN 1.4401 and their low-carbon variants EN 1.4307 and EN 1.4404 are the most commonly used within construction and these typically contain around 8$11 \%$ nickel. The nickel represents a large portion of the total material cost and thus high nickel prices and price volatility have a strong bearing on both the cost and price stability of stainless steel. While austenitic stainless steel remains the most favourable material choice in many applications, greater emphasis is now being placed on the development of alternative grades with lower nickel content. In this study, the material behaviour and compressive structural response of a lean duplex stainless steel (EN 1.4162), which contains approximately $1.5 \%$ nickel are examined. A total of eight stub column tests and twelve long column tests on lean duplex stainless steel square (SHS) and rectangular hollow sections (RHS) are reported. Precise measurements of material and geometric properties of the test specimens were also made, including the assessment of local and global geometric imperfections. The experimental studies were supplemented by finite element analysis and parametric studies were performed to generate results over a wider range of cross-sectional and member slenderness. Both the experimental and numerical results were used to assess the applicability of the Eurocode 3: Part 1-4 provisions regarding the Class 3 slenderness limit and effective width formula for internal elements in compression and the column buckling curve for hollow sections to lean duplex structural components. Comparisons between the structural performance of lean duplex stainless steel and that of other more commonly used stainless steel grades are also presented, showing lean duplex to be an attractive choice for structural applications.
\end{abstract}


Keywords: Buckling, Classification, Columns, Experiments, Finite element, Hollow section, Lean Duplex, Numerical modelling, Stainless steel, Stub columns.

\section{Introduction}

There is a wide variety of grades of stainless steels, providing a range of material characteristics to suit the demands of numerous, diverse engineering applications. Both overall, and within the construction industry, the austenitic grades feature most prominently [1]. The most commonly employed grades of austenitic stainless steel are EN 1.4301/1.4307 and EN 1.4401/1.4404, which contain around 8-11\% nickel [2]. Nickel stabilises the austenitic microstructure and therefore contributes to the associated favourable characteristics such as formability, weldability, toughness and high temperature properties. However, nickel also represents a significant portion of the cost of austenitic stainless steel and this has led, particularly in recent years to the development and evaluation of alternative grades of stainless steel with low nickel content.

Appropriate material selection, taking due account of in-service performance, economics and environmental conditions, involves matching the material characteristics to the particular demands of the application. Within construction, although austenitic stainless steels are the most widely specified, their strengths are often not fully utilised; a recently developed 'lean duplex' stainless steel, containing approximately $1.5 \%$ nickel, may offer a more appropriate balance of properties for structural applications. The particular grade considered in this study is EN 1.4162, which is generally less expensive and possesses higher strength than the familiar austenitics, while still retaining good corrosion resistance and high temperature properties [3], together with adequate weldability [4] and fracture toughness [5]. Examples of the use of lean duplex stainless steel in construction have already emerged [6], including footbridges in Förde, Norway and Siena, Italy; the latter is shown in Fig. 1.

Despite early applications of lean duplex stainless steel, its structural properties remain largely unverified as no test data on structural components have been reported to date. A research project is underway at Imperial College London to address these shortcomings, focusing initially on cold-formed hollow sections. Material properties derived from tensile and compressive coupon tests, slenderness limits for cross-section classification and effective 
width formulae for slender sections have been recently developed by the authors [7]. This paper examines the compressive behaviour of lean duplex stainless steel square and rectangular hollow sections (SHS and RHS respectively). Eight stub column tests and twelve flexural buckling tests have been carried out and are reported in detail herein. The test results were used to validate finite element (FE) models, which were thereafter employed in parametric studies, to expand the range of available structural performance data, studying the influence, in particular, of cross-section and member slenderness. Both the experimental and numerical results were used to assess the applicability of the European structural design provisions for stainless steel EN 1993-1-4 [8] to lean duplex stainless steel structural components. Comparisons with recent proposals made by the authors regarding the classification of stainless steel cross-sections [9], as well as comparisons with the structural performance of other commonly used structural stainless steel grades are also included.

\section{Experimental investigation}

\subsection{Introduction}

An experimental investigation into the structural performance of lean duplex stainless steel (grade EN 1.4162) SHS and RHS was conducted in the Structures Laboratory at Imperial College London. The laboratory testing program comprised tensile and compressive tests on flat coupons and tensile tests on corner coupons extracted from the cold-formed sections, eight three-point bending tests, eight stub column tests and twelve flexural buckling tests. The chemical composition of the tested material as given in the mill certificates is displayed in Table 1. A detailed description of the experimental set-up and the experimental results of the material tests and three-point bending tests is given in [7], whereas the stub column tests and flexural buckling tests are reported in detail in this section.

\subsection{Material properties}

The material properties derived from the coupon tests, which are used in the assessment of the member test results and the development of the FE models are given in Tables 2-4 for tensile flat, compressive flat and tensile corner material, respectively. The reported material 
parameters are the Young's modulus E, the $0.2 \%$ and $1 \%$ proof stresses $\sigma_{0.2}$ and $\sigma_{1.0}$, respectively, the ultimate tensile stress $\sigma_{\mathrm{u}}$, the plastic strain at fracture $\varepsilon_{\mathrm{f}}$ (based on elongation over the standard gauge length $5.65 \sqrt{\mathrm{A}}$, where $\mathrm{A}$ is the cross-sectional area of the coupon), and the strain hardening exponents $\mathrm{n}$ and $\mathrm{n}_{0.2,1.0}$ used in the compound Ramberg-Osgood material model [10-13], which is a two-stage version of the basic Ramberg-Osgood model $[14,15]$. The key minimum specified material properties for grade EN 1.4162 stainless steel cold-rolled strip, as defined in [16], and included in EN 10088-4 [2], are as follows: $\sigma_{0.2}=530$ $\mathrm{N} / \mathrm{mm}^{2}, \sigma_{\mathrm{u}}=700-900 \mathrm{~N} / \mathrm{mm}^{2}, \varepsilon_{\mathrm{f}}=30 \%$ (over a gauge length $5.65 \sqrt{\mathrm{A}}$ ).

\subsection{Stub column tests}

Four section sizes were employed for the stub column tests, namely SHS $100 \times 100 \times 4$, SHS $80 \times 80 \times 4$, SHS $60 \times 60 \times 3$ and RHS $80 \times 40 \times 4$. Two repeated concentric compression tests were carried out for each of the cross-section sizes to enable the determination of a suitable Class 3 limit for lean duplex stainless steel internal elements in compression. All specimens were cold-rolled and seam welded. A stub column length equal to four times its mean nominal cross-sectional width was chosen, which is deemed long enough to include a representative pattern of residual stresses and geometric imperfections, yet short enough to avoid overall flexural buckling [17].

Measurements of the basic geometry and initial geometric imperfections of the specimens were conducted prior to testing. The geometric imperfections measurements followed the procedure reported by Schafer and Peköz in [18]. Local geometric imperfections were measured only over the middle half of each specimen's length in order to eliminate the effect of end flaring, which results from the release of residual stresses following cutting operations [19]. The same approach has been successfully adopted in previous studies [20, 21]. The maximum measured local geometric imperfection $\mathrm{w}_{0}$ for each nominal stub column dimension is given in Table 5. Table 5 also includes the measured geometry (see Fig. 2) of each stub column specimen, where $\mathrm{L}$ is the stub column length, $\mathrm{B}$ is the section width, $\mathrm{H}$ is the section depth, $\mathrm{t}$ is the thickness and $\mathrm{r}_{\mathrm{i}}$ is the internal corner radius.

The ends of the stub columns were milled flat and square and were compressed between parallel plattens in a self contained $300 \mathrm{~T}$ Amsler hydraulic testing machine as depicted in 
Fig. 3. The instrumentation consisted of four LVDTs to measure the end shortening between the flat plattens, a load cell to accurately record the applied load and four strain gauges, affixed at the mid-height at each specimen in the configuration shown in Fig. 3. The strain readings were used initially to verify that the load was being applied concentrically and later to eliminate the effect of the elastic deformation of the plattens $[12,20,22]$. To verify concentricity of loading, a small alignment load, approximately equal to $10 \%$ of the estimated failure load was applied and the variation in strain around the cross-section was checked; in all cases, individual strain gauge readings varied less than 5\% from the average strain, which was deemed acceptable. All data (load, voltage, strains and displacements) were recorded at two seconds intervals using the data acquisition system DATASCAN.

Tests were continued beyond the ultimate load-carrying capacity of the stub columns, and the post-ultimate response was recorded. The ultimate load and the corresponding end shortening at ultimate load are given in Table 6, while the full load-end shortening curves for the tested specimens are depicted in Fig. 4. Note that the reported end shortening curves and the endshortening values corresponding to ultimate load given in Table 6 refer to the true stub column shortening, which is obtained on the basis of the recorded LVDT and strain readings according to the procedure recommended in [22]. Failure was due to local buckling though often after considerable plastic deformation; typical failure modes are depicted in Fig. 5.

\subsection{Flexural buckling tests}

Having established the basic material and cross-sectional response, twelve flexural buckling tests were carried out in order to obtain ultimate load carrying capacity data and assess the suitability of the current codified buckling curve for hollow sections [8] for lean duplex stainless steel SHS and RHS. The tests were conducted on pin-ended columns with nominal cross-sectional dimensions of $80 \times 80 \times 4,60 \times 60 \times 3$ and $80 \times 40 \times 4$, in a similar fashion to the tests described in [20]. Both minor and major axis buckling were considered for the RHS $80 \times 40 \times 4$ specimens. The specimen lengths were chosen such that the buckling lengths (i.e. total distance between knife edges) were equal to $800 \mathrm{~mm}, 1200 \mathrm{~mm}, 1600 \mathrm{~mm}$ and 2000 $\mathrm{mm}$. This provided a range of non-dimensional member slendernesses, defined through by Eq. (1), in accordance with Eurocode 3: Part 1.4 [8], from 0.57 to 2.02. 
$\bar{\lambda}=\sqrt{\mathrm{A} \sigma_{0.2} / \mathrm{N}_{\mathrm{cr}}}$

where $\mathrm{A}$ is the cross-sectional area, $\sigma_{0.2}$ is the $0.2 \%$ proof stress and $\mathrm{N}_{\mathrm{cr}}$ is the elastic critical buckling load of the column.

All tests were carried out in a $600 \mathrm{kN}$ Instron capacity rig under displacement control. Knife edges were employed to achieve the pin-ended boundary conditions, as shown in Fig. 6, where the test rig is also depicted. A close-up of the knife edges is depicted in Fig. 7. The employed instrumentation may also be seen in Fig. 6 and consisted of a load cell attached to the top knife edge, two pairs of LVDTs at each end of the column measuring end rotations and end shortening and two string pots attached at the mid-height of the columns measuring the lateral deflection of the specimens.

Measurements of the specimen geometry, including initial global geometric imperfections $\mathrm{e}_{0}$ were conducted prior to testing and are reported in Table 7. The measured overall geometric imperfections were generally small and hence the load was applied eccentrically at the ends such that the combined effects of initial bow and loading eccentricity gave a total eccentricity at mid-height of $\mathrm{L} / 1500$, where $\mathrm{L}$ is the pin-ended column buckling length. This value is the statistical mean of geometric imperfections in steel structural members [23].

All columns failed by flexural buckling without any visible sign of local buckling. The full load-lateral displacement curves were recorded and are shown in Figs. 8 and 9 for SHS and RHS columns respectively. The key results from the column tests, including the ultimate load and the lateral displacement at ultimate load are reported in Table 8. All obtained test results have been used in the validation of the numerical models, as described in Section 3, and are analysed and discussed in detail in Section 4 of the present paper.

\section{Numerical modelling}

\subsection{Basic modelling assumptions}


The tests reported in the previous section have been utilised to validate FE models and generate additional results by means of parametric studies, thus enabling a thorough assessment of the key parameters affecting the structural response of lean duplex stainless steel compression members. The general purpose finite element analysis package ABAQUS [24] was used for all numerical studies reported in this paper. The FE simulations followed the proposals regarding numerical modelling of stainless steel components reported in [25, 26].

Measured geometric properties reported in Tables 5 and 7 for stub columns and long columns, respectively, have been employed in the FE models. Owing to the thin-walled nature of tubular sections, and in line with similar previous investigations [7, 20, 25, 26, 27], shell elements were employed to discretise the models. The 4-noded doubly curved shell element with reduced integration S4R [24] has been utilised in this study. As discussed later, it was assumed that the corner properties, as derived from the corner coupon tests, extended up to a distance equal to two times the material thickness into the flat region of each face of the models on either side of the corners. Two elements were utilised to discretise each of these flat parts adjacent to the corners and hence, in order to maintain a uniform mesh size within all flat parts of the models, an element size equal to the material thickness was required for all models. A coarser, non-uniform mesh was shown to yield results of similar accuracy but given the low computational cost associated with the finer mesh size, a uniform mesh was employed. Regarding the root radii, three elements were used to discretise them, assuming that their geometry is approximated by circular arcs.

Geometry, boundary conditions, applied loads and failure modes of the tested components were observed to be symmetric. The displayed symmetry was exploited in the finite element modelling with suitable boundary conditions applied along the symmetry axes, enabling significant savings in computational time. Regarding the stub columns, only a quarter of the section was modelled, whereas for the long columns, half of the cross-section was discretised. For both stub columns and long columns the full component length was modelled. All degrees of freedom were restrained at the end cross-sections of the stub column models, apart from vertical translation at the loaded end, which was constrained via kinematic coupling to follow the same vertical displacement. Similar boundary conditions were applied to the flexural buckling models, with the only difference lying in the rotational degree of freedom about the 
axis of buckling of the end cross-sections, which was not restrained, thus enabling the modelling of the pin-ended boundary conditions.

It has been experimentally verified that the cold-forming process induces strength enhancements in the corner regions of cold-formed components for carbon steel [28] and stainless steel [29]. The enhanced strength also extends beyond the curved corner regions into the flat parts of the cross-section. A quantitative assessment of the effect of cold-forming on the stress-strain response of lean duplex stainless steel can be found in [7]. Previous studies $[25,26]$ suggest that the best agreement between experimental and FE results for cold-rolled stainless steel hollow sections is obtained when the corner properties extend into the flat regions by a distance equal to two times the material thickness. This has been verified by experimental observations in the corner regions [29], and this approach has been followed in the present study. The material properties derived from tensile corner tests (as reported in Table 4) were assigned to the corner regions of the models and the adjacent flat regions up to two times the material thickness, whereas compressive material properties (as reported in Table 3) were assigned to the remainder of the sections.

Residual stresses in cold-formed tubular sections may be categorised as (1) bending residual stresses that vary through the thickness of the sections and arise as a result of plastic deformation during forming and (2) membrane residual stresses that are induced during the seam-welding operation to complete the tube. Careful measurements [30] have shown the latter to be relatively insignificant in stainless steel hollow sections and largely swamped by the dominant bending residual stresses. Furthermore, the effect of the bending residual stresses is inherently present in the material stress-strain properties [30, 31] since the residual stresses that are released during the cutting of the coupons (causing longitudinal curvature) are essentially reintroduced by straightening of the coupons during testing. Residual stresses were not therefore explicitly introduced into the described models, but their influence was present in the material modelling.

As mentioned in Section 2.1, a compound version [10-13] of the basic Ramberg-Osgood material model $[14,15]$ was employed to simulate the stress-strain response of lean duplex stainless steel, with the respective material parameters given in Tables 3-5. For incorporation into the FE analyses, this material model was approximated with a multilinear curve, the points of which were distributed proportionally to curvature of the original continuous curve 
[32], following a procedure described in [33], in order to minimise the error introduced by the approximation. These points were thereafter converted into true stress $\sigma_{\text {true }}$ and log plastic strain $\varepsilon_{\mathrm{ln}}^{\mathrm{pl}}$, as defined by Eqs. (2) and (3)

$$
\begin{aligned}
& \sigma_{\text {true }}=\sigma_{\text {nom }}\left(1+\varepsilon_{\text {nom }}\right) \\
& \varepsilon_{\ln }^{\mathrm{pl}}=\ln \left(1+\varepsilon_{\text {nom }}\right)-\frac{\sigma_{\text {true }}}{E}
\end{aligned}
$$

where $\sigma_{\text {nom }}$ and $\varepsilon_{\text {nom }}$ are the engineering stress and strain respectively and $E$ is the Young's modulus.

Based on the aforementioned modelling assumptions, a series of FE models were generated. Linear eigenvalue buckling analyses using the subspace iteration method were initially performed to extract the buckling mode shapes. These served as initial geometric imperfection patterns used in the subsequent geometrically and materially non-linear analyses. The modified Riks method [24], which is essentially a variation of the classical arclength method, was employed for the non-linear analyses to enable the full load-deflection response, including into the post-ultimate range to be simulated.

The lowest local buckling mode shape was utilised to perturb the geometry of the stub columns, while both the first local and first global mode shapes were introduced as geometric imperfections in the flexural buckling models. Four variations of the local imperfection amplitude were considered in the non-linear analyses; the maximum measured imperfection reported in Table 5, 1/10 and 1/100 of the cross-sectional thickness and the imperfection amplitude derived from the predictive model of [34] as adapted for stainless steels [25], given by Eq. (4)

$$
\mathrm{w}_{0}=0.023\left(\frac{\sigma_{0.2}}{\sigma_{\mathrm{cr}}}\right) \mathrm{t}
$$

where $\sigma_{0.2}$ is the tensile $0.2 \%$ proof stress given in Table 2 and $\sigma_{\mathrm{cr}}$ is the elastic critical buckling stress of the most slender of the constituent plate element in the section, determined 
on the basis of the flat width of the element. For the global imperfection amplitudes, four fractions of the respective buckling length were considered, namely $\mathrm{L} / 500, \mathrm{~L} / 1000, \mathrm{~L} / 1500$ and $\mathrm{L} / 2000$, noting that $\mathrm{L} / 1500$ represents the experimental imperfection.

\subsection{Validation of models and parametric studies}

In this section the results of the numerical simulations and the tests are compared, and the sensitivity of the models to the key modelling parameters, particularly the imperfection amplitudes, are examined. Comparisons with the test results are made to assess the accuracy of the models and verify their suitability for performing parametric studies.

Table 9 presents the ratios of the numerical to experimental ultimate loads and corresponding displacements at ultimate load for the varying imperfection amplitudes. The ultimate load is generally well-predicted for the measured imperfection amplitude, the amplitude predicted by the Dawson and Walker model (Eq. (4)) and $t / 100$, whereas the use of the $t / 10$ value results in a clear underestimation of the load carrying capacity of the stub columns. The end shortening at ultimate load appears to be more sensitive to the initial imperfection amplitude and is best predicted when an imperfection amplitude from the Dawson and Walker model or $t / 100$ is used. The Dawson and Walker model predicts imperfection amplitudes on the basis of both geometric and material properties of cross-sections. It has been shown, as in the current study, to provide suitable local imperfections for inclusion in numerical models to accurately simulate tests [25-27], and to provide a means of predicting measured imperfection amplitudes directly $[19,25]$. This model was therefore employed in the parametric studies described in this paper to derive local imperfection amplitudes for both the stub columns and long columns.

Overall excellent agreement between the experimental stub column results and those obtained from the FE simulations was achieved; the compressive response was accurately predicted throughout the full loading history, including initial stiffness, ultimate load, displacement at ultimate load and post-ultimate response. Figs. 10 and 11 depict the experimental and numerical load-end shortening curves using the imperfection amplitude predicted by the Dawson and Walker model for the $80 \times 40 \times 4-\mathrm{SC} 2$ and $80 \times 80 \times 4$-SC2 stub columns, whereas a comparison of experimental and numerical failure modes is displayed in Fig. 12. 
Good agreement between test and numerical results is also displayed for the flexural buckling specimens. Comparisons are shown in Table 10, where it may be seen, as expected, that the ratio of the numerically predicted ultimate buckling load to the experimental buckling load is clearly influenced by the assumed initial global imperfection amplitude. The most accurate and consistent prediction of test response is obtained for an imperfection amplitude of $\mathrm{L} / 1500$, which coincides with the total imperfection amplitude (initial bow imperfection plus eccentricity) present in the tests. Comparisons between experimental and FE results in terms of load versus lateral deflection are depicted in Figs. 13, 14 and 15 for an SHS column, an RHS column buckling about the major axis and an RHS column buckling about the minor axis, respectively. The FE failure modes also compare well with the test failure modes, as displayed in Fig. 16.

Upon validation of the FE models for both stub columns and long column parametric studies have been conducted. The generated models adhere to the basic modelling assumptions stated in Section 3.1. The material properties adopted in the FE parametric studies were based on the averaged experimental material stress-strain curves; flat compressive and corner tensile material properties were assigned to the respective parts of the models. Local geometric imperfections in the form of the lowest buckling mode shape with an amplitude derived from Eq. (4) were incorporated for both stub column and flexural buckling models, whereas the global imperfection amplitude of the long columns was taken as L/1500.

All cross-sections considered in the parametric studies had an outer width B equal to $100 \mathrm{~mm}$ and an outer height $\mathrm{H}$ equal to either $100 \mathrm{~mm}$ or $200 \mathrm{~mm}$, thereby resulting into aspect ratios of 1.0 and 2.0. The length of the stub column models was set equal to four times their mean outer dimension, hence $400 \mathrm{~mm}$ for the SHS and $600 \mathrm{~mm}$ for the RHS models, while their thickness varied from $1.6 \mathrm{~mm}$ to $13.0 \mathrm{~mm}$ to encompass a wide range of cross-sectional slendernesses. The cross-section slenderness was defined as $\mathrm{c} / \mathrm{t} \varepsilon$ in accordance with Eurocode 3: Part 1-4 [8], where $\mathrm{c}$ is the flat element width, $\mathrm{t}$ is the element thickness and $\varepsilon=\sqrt{\left(235 / \mathrm{f}_{\mathrm{y}}\right)(\mathrm{E} / 210000)}$. Regarding the flexural buckling models, constant thicknesses of $4.75 \mathrm{~mm}$ and $9.50 \mathrm{~mm}$ were selected for the $100 \times 100$ and $100 \times 200$ cross-sections respectively, resulting in Class 3 cross-sections according to the slenderness limits given in [8] - the actual $\mathrm{c} / \mathrm{t} \varepsilon$ ratio was 30 , compared to the Class 3 slenderness limit of 30.7. The buckling length of the columns was varied to cover a wide spectrum of member slendernesses 
ranging from 0.4 to 2.4 . The results of the parametric studies are discussed in the following section.

\section{Analysis of results and design recommendations}

\subsection{Introduction}

In this section, the applicability of the provisions of Eurocode 3: Part 1.4 [8], including the Class 3 slenderness limit and effective width formula for internal elements in compression and the buckling curve for hollow section columns to lean duplex stainless steel structural components is assessed on the basis of both the experimental and numerical results reported in this paper. Furthermore, the modified slenderness limits and effective width formulae for stainless steel cross-sections, proposed by the authors on the basis of a significantly larger experimental data pool than was available at the time of development of Eurocode 3: Part 1.4 in [9], are also assessed. Finally, comparisons of the structural performance of lean duplex stainless steel with that of the more common stainless steel grades in construction are made. In all code comparisons, the measured tensile material properties derived for each crosssection from flat tensile coupon tests were utilised.

\subsection{Class 3 slenderness limit for elements in compression}

The obtained test and FE data were used to assess the applicability of the codified slenderness limits to lean duplex stainless steel elements. For all experimental and numerical stub column results, the ultimate load divided by the squash load, $\mathrm{F}_{\mathrm{u}} / A \sigma_{0.2}$, is plotted against the slenderness of the most slender constituent element in the cross-section in Fig. 17, where the respective Class 3 limits for carbon steel and stainless steel specified by Eurocode 3: Part 1.1 [35] and Eurocode 3: Part 1.4 [8], as well as the Class 3 limit proposed in [9] are also included.

As shown in Fig. 17, the RHS $(\mathrm{H} / \mathrm{B}=2.0)$ display superior load carrying capacity to their SHS $(\mathrm{H} / \mathrm{B}=1.0)$ counterparts of equal cross-sectional slenderness (i.e. $\mathrm{c} / \mathrm{t} \varepsilon)$. This is due to the higher level of restraint offered by the narrow faces to the wider (more slender) faces of the 
RHS and the potential for stress redistribution once local buckling of the wider face plates occurs. In order to maintain simplicity, the effect of element interaction on the cross-sectional response is not accounted for in [8] or [35] and a conservative cross-section classification approach is specified, according to which all elements are treated in isolation and the crosssectional response relates to its most slender element. More advanced approaches accounting for element interaction have been derived for hot-rolled carbon steel H-sections [36], coldformed carbon steel sections [37] and cold-formed stainless steel sections [38].

Within the current cross-section classification approach codified in [8], the Class 3 limit (i.e. the limit below which an element can be assumed to be fully effective) of $30.7 \varepsilon$ is conservative and could be relaxed to $37 \varepsilon$, as proposed by the authors [9] for other grades of stainless steel. The respective carbon steel Class 3 limit of $42 \varepsilon$ is marginally unconservative and does not provide adequate reliability as assessed by the statistical analysis conducted in [9], according to Annex D of EN 1990 [39].

\subsection{Effective width formula}

Slender (Class 4) cross-sections are treated in Eurocode 3: Part 1-4 [8] following the Von Karman effective width approach, as modified according to experimental data of Winter [4042], to account for the occurrence of local buckling prior to reaching the $0.2 \%$ proof strength. The effective width equation for internal elements given in Eurocode 3: Part 1.4 is compatible with the corresponding codified Class 3 limit of $30.7 \varepsilon$, which has been shown to be rather conservative. For consistency with the revised limit of $37 \varepsilon$, a revised effective width equation was proposed [9], as given by Eq. (5):

$\rho=\frac{0.772}{\bar{\lambda}_{\mathrm{p}}}-\frac{0.079}{\bar{\lambda}_{\mathrm{p}}^{2}} \leq 1$

where $\rho$ is the reduction factor for local buckling and $\bar{\lambda}_{\mathrm{p}}$ is the element slenderness, as defined in [8]. The Class 3 limits set out in [8] and [9] and the $F_{\mathrm{u}} / \mathrm{F}_{\mathrm{y}}$ (ultimate load normalised by the squash load) ratios predicted according to the respective effective width equations are plotted together with the $\mathrm{F}_{\mathrm{u}} / \mathrm{F}_{\mathrm{y}}$ data points derived from parametric studies against the $\mathrm{c} / \mathrm{t} \varepsilon$ ratio of the most slender plate element in Fig. 18. The results confirm the adequacy but 
conservatism of the current Eurocode 3: Part 1.4 provisions and the applicability of the proposed revised formula (Eq. (5)) [9].

\subsection{Flexural buckling}

The applicability of the buckling curve specified in Eurocode 3: Part 1.4 for hollow sections to lean duplex stainless steel tubular columns is assessed by comparing the column test and numerical data with the respective codified predictions. For both experimental and FE results, the ultimate load has been normalised by the corresponding squash load (defined as $A \sigma_{0.2}$ ) and plotted against the non-dimensional slenderness $\bar{\lambda}$ in Fig. 19, where the stub column test data are also included. The effect of the aspect ratio is insignificant for slender columns, but becomes increasingly important with decreasing member slenderness, because of the increasing influence of cross-sectional behaviour (i.e. local buckling). Good agreement between the test data and code predictions is observed and hence application of the current buckling curve $\left(\bar{\lambda}_{0}=0.4\right.$ and $\left.\alpha=0.49\right)$ to lean duplex stainless steel SHS and RHS columns is proposed in the present paper.

\subsection{Comparison of lean duplex with other stainless steel grades}

The initial material cost of stainless steel comprises two components: the basic manufacturing cost and the alloy adjustment factor, which depends on the alloying elements used and hence varies markedly between grades. Lean duplex stainless steel only contains approximately $1.5 \%$ nickel, resulting in a relatively low alloy adjustment factor and hence a competitive initial material cost [43]. In Figs. 20 and 21 the structural response of stub columns and long columns of the most commonly adopted structural stainless steel grades (i.e. austenitic and duplex grades) is compared with the corresponding lean duplex test data reported herein. The stub column data included in Fig. 20 have been reported in [12, 44-49], whereas the flexural buckling data were taken from [45-48, 50, 51]. In the determination of the slenderness parameter plotted on the horizontal axis of Figs. 20 and 21, only geometric properties have been included (c/t for stub columns and $\mathrm{L}_{\mathrm{cr}} / \mathrm{i}$, where $\mathrm{L}_{\mathrm{cr}}$ is the buckling length and $\mathrm{i}$ is the radius of gyration, for long columns), so that the effect of material is accounted for only in the vertical axis. In the high slenderness regime all stainless steel grades exhibit similar structural capacities since failure is governed principally by stiffness. However, for stockier cross- 
sections and members the lean duplex and conventional duplex structural components behave similarly and exhibit superior performance to their austenitic counterparts of similar geometric slenderness, since their higher strength can be fully utilized.

\section{Conclusions}

Eight stub column tests and twelve flexural buckling tests on lean duplex stainless steel SHS and RHS have been reported in detail in the present paper. The results of the experimental investigation were supplemented by numerically generated data. Upon validation of the FE models, parametric studies were conducted to investigate the structural response over a wide range of cross-sectional slenderness for the stub columns and member slenderness for the long columns. Based on both experimental and numerical data, the provisions of Eurocode 3: Part 1-4 for the classification and local buckling treatment of internal elements in compression and buckling for stainless steel hollow section columns, were assessed. Both the class 3 limit and the corresponding effective width equation for internal elements in compression was shown to be adequate but conservative and the adoption of the more favourable slenderness limits and effective width formulae [7] for stainless steel elements is supported herein. Regarding the flexural buckling response of lean duplex stainless steel columns, the current buckling curve for stainless steel hollow sections is deemed suitable. Overall, lean duplex stainless steel is shown to offer superior structural performance compared to the austenitic grades and at a lower cost [43], which represents a significant economic advantage and renders lean duplex stainless steel an attractive choice for structural applications.

\section{Acknowledgements}

The authors are grateful to Stalatube Finland for the supply of test specimens, to the UK Outokumpu Stainless Steel Research Foundation for funding of the project and would like to thank Stephanie Bouhala, Cheryl Parmar and Gordon Herbert for their contribution to the experimental part of this research. 


\section{References}

[1] Gardner, L. (2005). The use of stainless steel in structures. Progress in Structural Engineering and Materials. 7(2), 45-55.

[2] EN 10088-4. (2009) Stainless steels - Part 4: Technical delivery conditions for sheet/plate and strip of corrosion resisting steels for general purposes. CEN.

[3] Gardner, L., Insausti, A., Ng, K. T. and Ashraf, M. (submitted). Elevated temperature material properties of stainless steel alloys. Engineering Structures.

[4] Nilsson, J. O., Chai, G. and Kivisäkk, U. (2008). Recent development of stainless steels, Proceedings of the Sixth European Stainless steel Conference, pp. 585-590, Finland.

[5] Sieurin, H., Sandström, R. and Westin, E.M. (2007). Fracture toughness of the lean duplex stainless steel LDX 2101. Metallurgical and Materials Transactions A, 37(10), 2975-2981.

[6] Gedge, G. (2008). Structural uses of stainless steel - buildings and civil engineering. Journal of Constructional Steel Research, 64(11), 1194-1198.

[7] Theofanous, M. and Gardner, L. (submitted). Experimental and numerical studies on lean duplex stainless steel beams. Journal of Structural Engineering, ASCE.

[8] EN 1993-1-4. (2006) Eurocode 3: Design of steel structures - Part 1.4: General rules Supplementary rules for stainless steel. CEN.

[9] Gardner, L. and Theofanous, M. (2008). Discrete and continuous treatment of local buckling in stainless steel elements. Journal of Constructional Steel Research. 64(11), $1207-$ 1216. 
[10] Mirambell, E. and Real, E. (2000). On the calculation of deflections in structural stainless steel beams: an experimental and numerical investigation. Journal of Constructional Steel Research. 54(1), 109-133.

[11] Rasmussen, K.J.R. (2003). Full-range stress-strain curves for stainless steel alloys. Journal of Constructional Steel Research. 59(1), 47-61.

[12] Gardner, L. and Nethercot, D.A. (2004). Experiments on stainless steel hollow sections Part 1: Material and cross-sectional behaviour. Journal of Constructional Steel Research. 60(9), 1291-1318.

[13] Gardner, L. and Ashraf, M. (2006). Structural design for non-linear metallic materials. Engineering Structures. 28(6), 926-934.

[14] Ramberg, W. and Osgood, W. R. (1943). Description of stress-strain curves by three parameters. Technical Note No 902, National Advisory Committee for Aeronautics Washington, D.C.

[15] Hill, H.N. (1944). Determination of stress-strain relations from offset yield strength values. Technical Note No 927, National Advisory Committee for Aeronautics. Washington, D.C.

[16] Outokumpu data sheet (2009). LDX 2101®, 2304, 2205 - Duplex Steels for Structural Hollow Sections. http://www.outokumpu.com/42329.epibrw

[17] Galambos, T.V. Guide to Stability Design Criteria for Metal Structures. J. Wiley \& Sons, New York, 1998 (5th Ed.).

[18] Schafer, B.W. and Peköz, T. (1998). Computational modelling of cold-formed steel: characterizing geometric imperfections and residual stresses. Journal of Constructional Steel Research 47(3), 193-210.

[19] Cruise, R.B. and Gardner, L. (2006). Measurement and prediction of geometric imperfections in structural stainless steel members. Structural Engineering and Mechanics. 24(1), 63-89. 
[20] Theofanous, M., Chan, T.M. and Gardner, L. (2009). Structural response of stainless steel oval hollow section compression members. Engineering Structures, 31(4): 922-934.

[21] Becque, J. and Rasmussen, K. J. R. (in press). Experimental Investigation of the Interaction of Local and Overall Buckling of Stainless Steel I-Columns. Journal of Structural Engineering-ASCE.

[22] Compression tests of stainless steel tubular columns. (1990). Investigation Report S770. University of Sydney. Centre for Advanced Structural Engineering.

[23] Bjorhovde R. (1972). Deterministic and probabilistic approaches to the strength of steel columns. Bethelehem (PA): Lehigh University.

[24] Hibbitt, Karlsson \& Sorensen, Inc (2006). ABAQUS. ABAQUS/Standard user's manual volumes I-III and ABAQUS CAE manual. Version 6.6. (Pawtucket, USA).

[25] Gardner, L. and Nethercot D.A. (2004). Numerical Modeling of Stainless Steel Structural Components-A Consistent Approach. Journal of Structural Engineering, ASCE. 130(10), 1586-1601.

[26] Ashraf, M., Gardner, L. and Nethercot, D.A. (2006). Finite element modelling of structural stainless steel cross-sections. Thin-walled structures 44(2006) 1048-1062.

[27] Gardner, L., Talja, A. and Baddoo, N.R. (2006). Structural design of high-strength austenitic stainless steel. Thin-Walled Structures, 44(5), 517-528.

[28] Karren, K.W. (1967). Corner properties of cold-formed steel shapes. Journal of the Structural Division, ASCE. ST1, 401-432.

[29] Cruise, R.B. and Gardner, L. (2008). Strength enhancements induced during cold forming of stainless steel sections. Journal of Constructional Steel Research. 64 (11), 13101316. 
[30] Cruise, R.B. and Gardner, L. (2008). Residual stress analysis of structural stainless steel sections. Journal of Constructional Steel Research. 64(3), 352-366.

[31] Rasmussen K.J.R. and Hancock G.J. (1993). Design of cold-formed stainless steel tubular members. I: Columns. Journal of Structural Engineering, ASCE , 119(8), 2349-2367.

[32] Koltsakis, E.K. and Preftitsi, F.G. (2008). Numerical investigation of the plastic behaviour of short welded aluminium double-T beams. Engineering Structures 30 (7), 20222031.

[33] Theofanous, M., Chan, T.M. and Gardner, L. (2009). Flexural behaviour of stainless steel oval hollow sections. Thin-Walled Structures; 47(6-7): 776-787.

[34] Dawson, R.G. and Walker, A.C. (1972). Post-buckling of geometrically imperfect plates. Journal of the Structural Division, ASCE. 98:ST1, 75-94.

[35] EN 1993-1-1. (2005) Eurocode 3: Design of steel structures - Part 1.1: General rules General rules and rules for buildings. CEN.

[36] Kato B. (1989). Rotation capacity of H-section members as determined by local buckling. Journal of Constructional Steel Research, 13 (2-3), 95-109.

[37] Schafer, B.W. (2008). Review: The Direct Strength Method of cold-formed steel member design. Journal of Constructional Steel Research. 64 (7-8), 766-778.

[38] Theofanous, M. and Gardner, L. (submitted). The effect of element interaction on the ultimate capacity of stainless steel cross-sections. Thin-Walled Structures.

[39] EN 1990 (2002). Eurocode - Basis of structural design. CEN.

[40] Winter, G. (1947). Strength of thin steel compression flanges. Bulletin No. 35/3, Engrg. Experiment Sta., Cornell University, Ithaca, N.Y. 
[41] Winter, G. (1950). Performance of thin steel compression flanges. Bulletin No. 33, Engrg. Experiment Sta., Cornell University, Ithaca, N.Y.

[42] Johnson, A.L. and Winter, G. (1966). Behaviour of stainless steel columns and beams. Journal of the Structural Division, ASCE. ST5, 97-118.

[43] Outokumpu data sheet (2009). AAF (alloy adjustment factors) for flat products final figures. http://www.outokumpu.com/pages/Page 6001.aspx

[44] Kuwamura H. Local buckling consideration in design of thin-walled stainless steel members. Lecture at Pusan National University; 2001.

[45] Talja A. and Salmi P. (1995). Design of stainless steel RHS beams, columns and beamcolumns. Research note 1619. Finland: VTT Buidling Technology.

[46] Liu Y. and Young B. (2003). Buckling of stainless steel square hollow section compression members. Journal of Constructional Steel Research; 59(2):165-77.

[47] Young B. and Liu Y. (2003). Experimental investigation of cold-formed stainless steel columns. Journal of Structural Engineering, ASCE; 129(2):169-76.

[48] Young B. and Lui W.M. (2006). Tests on cold formed high strength stainless steel compression members. Thin-Walled Structures; 44(2):224-34.

[49] Young B. and Ellobody E. (2006). Experimental investigation of concrete-filled cold formed high strength stainless steel tube columns. Journal of Constructional Steel Research; 62(5):484-92.

[50] Gardner L. and Nethercot D.A. (2004). Experiments on stainless steel hollow sections Part 2: Member behaviour of columns and beams. Journal of Constructional Steel Research, 60(9), 1319-1332.

[51] Ala-Outinen, T. and Oksanen, T. (1997). Stainless steel compression members exposed to fire, Research Note 1684, VTT Building Technoloy, Finland. 
Table 1: Chemical composition ( $\%$ by weight) of test material

\begin{tabular}{c|cccccccccc}
\hline \hline Section & $\begin{array}{c}\mathrm{C} \\
(\%)\end{array}$ & $\begin{array}{c}\mathrm{Si} \\
(\%)\end{array}$ & $\begin{array}{c}\mathrm{Mn} \\
(\%)\end{array}$ & $\begin{array}{c}\mathrm{P} \\
(\%)\end{array}$ & $\begin{array}{c}\mathrm{S} \\
(\%)\end{array}$ & $\begin{array}{c}\mathrm{Cr} \\
(\%)\end{array}$ & $\begin{array}{c}\mathrm{Ni} \\
(\%)\end{array}$ & $\begin{array}{c}\mathrm{N} \\
(\%)\end{array}$ & $\begin{array}{c}\mathrm{Mo} \\
(\%)\end{array}$ & $\begin{array}{c}\mathrm{Cu} \\
(\%)\end{array}$ \\
\hline $\begin{array}{c}80 \times 60 \times 3 \\
80 \times 80 \times 4\end{array}$ & 0.025 & 0.8 & 4.99 & 0.02 & 0.001 & 21.64 & 1.5 & 0.209 & 0.3 & 0.31 \\
and $80 \times 40 \times 4$ & 0.028 & 0.7 & 4.85 & 0.021 & 0.001 & 21.4 & 1.6 & 0.229 & 0.26 & 0.29 \\
$100 \times 100 \times 4$ & 0.019 & 0.64 & 5.05 & 0.02 & 0.001 & 21.41 & 1.57 & 0.227 & 0.28 & 0.34 \\
\hline \hline
\end{tabular}

Table 2: Tensile flat material properties

\begin{tabular}{l|ccccccc}
\hline \hline & \multicolumn{1}{c}{$\begin{array}{c}\mathrm{E} \\
\text { Cross-section }\end{array}$} & $\begin{array}{c}\sigma_{0.2} \\
\left(\mathrm{~N} / \mathrm{mm}^{2}\right)\end{array}$ & $\begin{array}{c}\sigma_{1.0} \\
\left(\mathrm{~N} / \mathrm{mm}^{2}\right)\end{array}$ & $\begin{array}{c}\sigma_{\mathrm{u}} \\
\left(\mathrm{N} / \mathrm{mm}^{2}\right)\end{array}$ & $\begin{array}{c}\varepsilon_{\mathrm{f}} \\
\left(\mathrm{N} / \mathrm{mm}^{2}\right)\end{array}$ & $\begin{array}{c}\text { Compound } \\
\text { R-O coefficients }\end{array}$ \\
\hline SHS $100 \times 100 \times 4$ & 198800 & 586 & 632 & 761 & 47 & 9.0 & $\mathrm{n}$ \\
SHS $80 \times 80 \times 4$ & 199900 & 679 & 736 & 773 & 42 & 6.5 & 4.2 \\
SHS $60 \times 60 \times 3$ & 209800 & 755 & 819 & 839 & 44 & 6.0 & 4.3 \\
RHS $80 \times 40 \times 4$ & 199500 & 734 & 785 & 817 & 50 & 10.1 & 3.4 \\
\hline \hline
\end{tabular}


Table 3: Compressive flat material properties

\begin{tabular}{|c|c|c|c|c|c|}
\hline \multirow[t]{2}{*}{ Cross-section } & \multirow[t]{2}{*}{$\mathrm{E}\left(\mathrm{N} / \mathrm{mm}^{2}\right)$} & \multirow[t]{2}{*}{$\sigma_{0.2}\left(\mathrm{~N} / \mathrm{mm}^{2}\right)$} & \multirow[t]{2}{*}{$\sigma_{1.0}\left(\mathrm{~N} / \mathrm{mm}^{2}\right)$} & \multicolumn{2}{|c|}{ Compound R-O coefficients } \\
\hline & & & & $\mathrm{n}$ & $\mathrm{n}_{0.2,1.0}^{\prime}$ \\
\hline SHS $100 \times 100 \times 4$ & 198200 & 560 & 642 & 8.3 & 2.6 \\
\hline SHS $80 \times 80 \times 4$ & 197200 & 657 & 770 & 4.7 & 2.6 \\
\hline SHS $60 \times 60 \times 3$ & 206400 & 711 & 845 & 5.0 & 2.7 \\
\hline RHS $80 \times 40 \times 4$ & 204000 & 607 & 734 & 4.6 & 2.9 \\
\hline
\end{tabular}

Table 4: Tensile corner material properties

\begin{tabular}{l|ccccccc}
\hline \hline & & & & & & \multicolumn{2}{c}{ Compound } \\
Cross-section & $\begin{array}{c}\mathrm{E} \\
\left(\mathrm{N} / \mathrm{mm}^{2}\right)\end{array}$ & $\begin{array}{c}\sigma_{0.2} \\
\left(\mathrm{~N} / \mathrm{mm}^{2}\right)\end{array}$ & $\begin{array}{c}\sigma_{1.0} \\
\left(\mathrm{~N} / \mathrm{mm}^{2}\right)\end{array}$ & $\begin{array}{c}\sigma_{\mathrm{u}} \\
\left(\mathrm{N} / \mathrm{mm}^{2}\right)\end{array}$ & $\begin{array}{c}\varepsilon_{\mathrm{f}} \\
\%\end{array}$ & $\begin{array}{r}\text { R-O coefficients } \\
\mathrm{n}\end{array}$ & $\mathrm{n}_{0.2,1.0}^{\prime}$ \\
\hline SHS $100 \times 100 \times 4$ & 206000 & 811 & 912 & 917 & 32 & 6.3 & 4.1 \\
SHS $80 \times 80 \times 4$ & 210000 & 731 & 942 & 959 & 24 & 5.6 & 3.7 \\
SHS $60 \times 60 \times 3$ & 212400 & 885 & 1024 & 1026 & 22 & 6.3 & 4.0 \\
RHS $80 \times 40 \times 4$ & 213800 & 831 & 959 & 962 & 26 & 4.4 & 4.0 \\
\hline \hline
\end{tabular}


Table 5: Measured dimensions of stub columns

\begin{tabular}{l|ccccccc}
\hline \hline Specimen & $\mathrm{L}(\mathrm{mm})$ & $\mathrm{B}(\mathrm{mm})$ & $\mathrm{H}(\mathrm{mm})$ & $\mathrm{t}(\mathrm{mm})$ & $\mathrm{r}_{\mathrm{i}}(\mathrm{mm})$ & $\mathrm{A}\left(\mathrm{mm}^{2}\right)$ & $\mathrm{w}_{0}(\mathrm{~mm})$ \\
\hline $100 \times 100 \times 4-\mathrm{SC} 1$ & 400.0 & 101.0 & 102.0 & 3.93 & 3.8 & 1495.2 & 0.071 \\
$100 \times 100 \times 4-\mathrm{SC} 2$ & 400.0 & 102.0 & 103.0 & 3.97 & 3.9 & 1524.7 & 0.071 \\
$80 \times 80 \times 4-\mathrm{SC} 1$ & 319.7 & 80.0 & 80.5 & 3.88 & 3.8 & 1147.4 & 0.080 \\
$80 \times 80 \times 4-\mathrm{SC} 2$ & 332.2 & 80.0 & 80.0 & 3.81 & 3.6 & 1125.0 & 0.080 \\
$60 \times 60 \times 3-\mathrm{SC} 1$ & 239.8 & 60.0 & 60.0 & 3.09 & 2.3 & 683.0 & 0.062 \\
$60 \times 60 \times 3-\mathrm{SC} 2$ & 240.0 & 60.0 & 60.0 & 3.17 & 2.1 & 700.4 & 0.062 \\
$80 \times 40 \times 4-\mathrm{SC} 1$ & 239.9 & 39.0 & 79.5 & 3.76 & 3.5 & 799.8 & 0.058 \\
$80 \times 40 \times 4-\mathrm{SC} 2$ & 237.8 & 39.6 & 79.5 & 3.81 & 4.3 & 808.8 & 0.058 \\
\hline \hline
\end{tabular}

Table 6: Summary of test results for stub columns.

\begin{tabular}{l|cc}
\hline \hline Specimen & Ultimate $\operatorname{Load}_{\mathrm{u}}(\mathrm{kN})$ & End shortening at ultimate load $\delta_{\mathrm{u}}(\mathrm{mm})$ \\
\hline $100 \times 100 \times 4-\mathrm{SC} 1$ & 1022 & 3.63 \\
$100 \times 100 \times 4-\mathrm{SC} 2$ & 1037 & 4.01 \\
$80 \times 80 \times 4-\mathrm{SC} 1$ & 923 & 4.13 \\
$80 \times 80 \times 4-\mathrm{SC} 2$ & 915 & 3.88 \\
$60 \times 60 \times 3-\mathrm{SC} 1$ & 613 & 4.09 \\
$60 \times 60 \times 3-\mathrm{SC} 2$ & 616 & 3.69 \\
$80 \times 40 \times 4-\mathrm{SC} 1$ & 709 & 4.33 \\
$80 \times 40 \times 4-\mathrm{SC} 2$ & 710 & 4.12 \\
\hline \hline
\end{tabular}


Table 7: Measured geometric properties of columns

\begin{tabular}{l|cccccccc}
\hline \hline Specimen & $\begin{array}{c}\text { Axis of } \\
\text { buckling }\end{array}$ & $\mathrm{H}(\mathrm{mm})$ & $\mathrm{B}(\mathrm{mm})$ & $\mathrm{t}(\mathrm{mm})$ & $\begin{array}{c}\mathrm{r}_{\mathrm{i}} \\
(\mathrm{mm})\end{array}$ & $\mathrm{A}\left(\mathrm{mm}^{2}\right)$ & $\begin{array}{c}\text { Buckling } \\
\text { length } \\
\mathrm{L}_{\mathrm{cr}}(\mathrm{mm})\end{array}$ & $\begin{array}{c}\text { Global } \\
\text { imperfection } \\
\text { amplitude } \mathrm{e}_{0}(\mathrm{~mm})\end{array}$ \\
\hline $80 \times 80 \times 4-2000$ & - & 79.6 & 79.5 & 3.80 & 3.4 & 1116.7 & 1999.0 & 0.41 \\
$80 \times 80 \times 4-1200$ & - & 79.3 & 79.6 & 3.72 & 3.8 & 1091.0 & 1199.5 & 0.10 \\
$60 \times 60 \times 3-2000$ & - & 60.0 & 60.0 & 3.13 & 2.7 & 689.1 & 1999.0 & 0.31 \\
$60 \times 60 \times 3-1600$ & - & 59.6 & 60.0 & 3.15 & 2.4 & 692.4 & 1599.0 & 0.32 \\
$60 \times 60 \times 3-1200$ & - & 60.0 & 60.0 & 3.13 & 2.4 & 689.8 & 1199.0 & 0.26 \\
$60 \times 60 \times 3-800$ & - & 60.0 & 60.0 & 3.13 & 2.4 & 690.8 & 799.0 & 0.23 \\
$80 \times 40 \times 4-M I-1600$ & Minor & 39.0 & 79.2 & 3.80 & 4.3 & 800.4 & 1600.0 & 0.03 \\
$80 \times 40 \times 4-M J-1600$ & Major & 79.5 & 39.3 & 3.95 & 4.0 & 835.8 & 1599.5 & 0.25 \\
$80 \times 40 \times 4-M I-1200$ & Minor & 40.0 & 79.2 & 3.80 & 3.8 & 811.3 & 1199.0 & 0.15 \\
$80 \times 40 \times 4-M J-1200$ & Major & 79.6 & 39.5 & 3.96 & 3.6 & 842.4 & 1199.5 & 0.13 \\
$80 \times 40 \times 4-M I-800$ & Minor & 39.5 & 79.4 & 3.80 & 3.6 & 810.0 & 797.2 & 0.22 \\
$80 \times 40 \times 4-M J-800$ & Major & 79.9 & 39.5 & 3.93 & 4.1 & 835.6 & 799.0 & 0.28 \\
\hline \hline
\end{tabular}

Table 8: Key results from flexural buckling tests

\begin{tabular}{l|ccc}
\hline \hline Specimen & Non-dimensional slenderness $\bar{\lambda}$ & Ultimate load $\mathrm{F}_{\mathrm{u}}(\mathrm{kN})$ & Lateral deflection at $\mathrm{F}_{\mathrm{u}}(\mathrm{mm})$ \\
\hline $80 \times 80 \times 4-2000$ & 1.21 & 361.9 & 20.0 \\
$80 \times 80 \times 4-1200$ & 0.73 & 672.5 & 4.7 \\
$60 \times 60 \times 3-2000$ & 1.66 & 162.3 & 19.5 \\
$60 \times 60 \times 3-1600$ & 1.34 & 231.7 & 15.4 \\
$60 \times 60 \times 3-1200$ & 0.99 & 326.9 & 10.4 \\
$60 \times 60 \times 3-800$ & 0.66 & 445.9 & 5.9 \\
$80 \times 40 \times 4-\mathrm{MI}-1600$ & 2.02 & 160.4 & 4.1 \\
$80 \times 40 \times 4-\mathrm{MJ}-1600$ & 1.14 & 406.3 & 3.8 \\
$80 \times 40 \times 4-\mathrm{MI}-1200$ & 1.47 & 237.4 & 9.9 \\
$80 \times 40 \times 4-\mathrm{MJ}-1200$ & 0.86 & 497.7 & 7.7 \\
$80 \times 40 \times 4-\mathrm{MI}-800$ & 0.99 & 366.6 & 9.0 \\
$80 \times 40 \times 4-\mathrm{MJ}-800$ & 0.57 & 546.2 & 6.3 \\
\hline \hline
\end{tabular}


Table 9 Comparison of the stub column test results with FE results for varying imperfection amplitudes

\begin{tabular}{|c|c|c|c|c|c|c|c|c|}
\hline \multirow{2}{*}{$\begin{array}{l}\text { Stub column } \\
\text { designation }\end{array}$} & \multicolumn{2}{|c|}{$\begin{array}{l}\text { Measured } \\
\text { amplitude } \mathrm{w}_{0}\end{array}$} & \multicolumn{2}{|c|}{$\mathrm{t} / 10$} & \multicolumn{2}{|c|}{$\mathrm{t} / 100$} & \multicolumn{2}{|c|}{$\begin{array}{c}\text { Dawson and } \\
\text { Walker model }\end{array}$} \\
\hline & $\begin{array}{l}\mathrm{FE} \mathrm{F}_{\mathrm{u}} / \\
\text { Test } \mathrm{F}_{\mathrm{u}}\end{array}$ & $\begin{array}{l}\text { FE } \delta_{\mathrm{u}} / \\
\text { Test } \delta_{\mathrm{u}}\end{array}$ & $\begin{array}{l}\text { FE F } F_{u} / \\
\text { Test } F_{u}\end{array}$ & $\begin{array}{l}\mathrm{FE} \delta_{\mathrm{u}} / \\
\text { Test } \delta_{\mathrm{u}}\end{array}$ & $\begin{array}{l}\mathrm{FE} \mathrm{F}_{\mathrm{u}} / \\
\text { Test } \mathrm{F}_{\mathrm{u}}\end{array}$ & $\begin{array}{l}\mathrm{FE} \delta_{\mathrm{u}} / \\
\text { Test } \delta_{\mathrm{u}}\end{array}$ & $\begin{array}{l}\text { FE F F }_{\mathrm{u}} / \\
\text { Test } \mathrm{F}_{\mathrm{u}}\end{array}$ & $\begin{array}{l}\mathrm{FE} \delta_{\mathrm{u}} / \\
\text { Test } \delta_{\mathrm{u}}\end{array}$ \\
\hline $100 \times 100 \times 4-S C 1$ & 0.95 & 0.71 & 0.86 & 0.61 & 0.98 & 0.78 & 0.97 & 0.73 \\
\hline $100 \times 100 \times 4-\mathrm{SC} 2$ & 0.96 & 0.64 & 0.87 & 0.50 & 0.98 & 0.70 & 0.98 & 0.69 \\
\hline $80 \times 80 \times 4-\mathrm{SC} 1$ & 1.00 & 0.68 & 0.92 & 0.45 & 1.01 & 0.75 & 1.02 & 0.80 \\
\hline $80 \times 80 \times 4-\mathrm{SC} 2$ & 1.02 & 0.81 & 0.95 & 0.57 & 1.05 & 0.96 & 1.06 & 0.98 \\
\hline $60 \times 60 \times 3-\mathrm{SC} 1$ & 0.97 & 0.86 & 0.90 & 0.54 & 0.98 & 0.91 & 0.98 & 0.91 \\
\hline $60 \times 60 \times 3-\mathrm{SC} 2$ & 0.99 & 0.89 & 0.93 & 0.57 & 1.00 & 0.99 & 1.00 & 1.02 \\
\hline $80 \times 40 \times 4-\mathrm{SC} 1$ & 1.00 & 0.83 & 0.90 & 0.55 & 1.03 & 0.93 & 1.03 & 0.93 \\
\hline $80 \times 40 \times 4-\mathrm{SC} 2$ & 0.97 & 0.76 & 0.89 & 0.61 & 1.01 & 1.03 & 1.01 & 1.04 \\
\hline Mean & 0.98 & 0.77 & 0.90 & 0.55 & 1.00 & 0.88 & 1.01 & 0.89 \\
\hline $\mathrm{COV}$ & 0.02 & 0.12 & 0.03 & 0.10 & 0.03 & 0.14 & 0.03 & 0.15 \\
\hline
\end{tabular}


Table 10 Comparison of the column test results with FE results for varying imperfection amplitudes

\begin{tabular}{l|cccc}
\hline \hline \multirow{2}{*}{ Specimen } & \multicolumn{3}{|c}{$\mathrm{FE} \mathrm{F}_{\mathrm{u}} / \mathrm{Test} \mathrm{F}_{\mathrm{u}}$} \\
& $\mathrm{L} / 500$ & $\mathrm{~L} / 1000$ & $\mathrm{~L} / 1500$ & $\mathrm{~L} / 2000$ \\
\hline $80 \times 80 \times 4-2000$ & 0.96 & 1.03 & 1.06 & 1.08 \\
$80 \times 80 \times 4-1200$ & 0.89 & 0.94 & 0.95 & 0.96 \\
$60 \times 60 \times 3-2000$ & 0.94 & 1.00 & 1.03 & 1.04 \\
$60 \times 60 \times 3-1600$ & 0.93 & 0.99 & 1.02 & 1.04 \\
$60 \times 60 \times 3-1200$ & 0.94 & 1.00 & 1.03 & 1.04 \\
$60 \times 60 \times 3-800$ & 0.99 & 1.01 & 1.02 & 1.03 \\
$80 \times 40 \times 4-\mathrm{MI}-1600$ & 0.81 & 0.87 & 0.89 & 0.90 \\
$80 \times 40 \times 4-\mathrm{MJ}-1600$ & 0.85 & 0.90 & 0.93 & 0.94 \\
$80 \times 40 \times 4-\mathrm{MI}-1200$ & 0.87 & 0.93 & 0.96 & 0.97 \\
$80 \times 40 \times 4-\mathrm{MJ}-1200$ & 0.90 & 0.94 & 0.96 & 0.98 \\
$80 \times 40 \times 4-\mathrm{MI}-800$ & 0.92 & 0.97 & 0.99 & 1.00 \\
$80 \times 40 \times 4-\mathrm{MJ}-800$ & 1.01 & 1.05 & 1.07 & 1.08 \\
\hline Mean & 0.92 & 0.97 & 0.99 & 1.01 \\
$\mathrm{COV}$ & 0.06 & 0.06 & 0.05 & 0.05 \\
\hline \hline
\end{tabular}




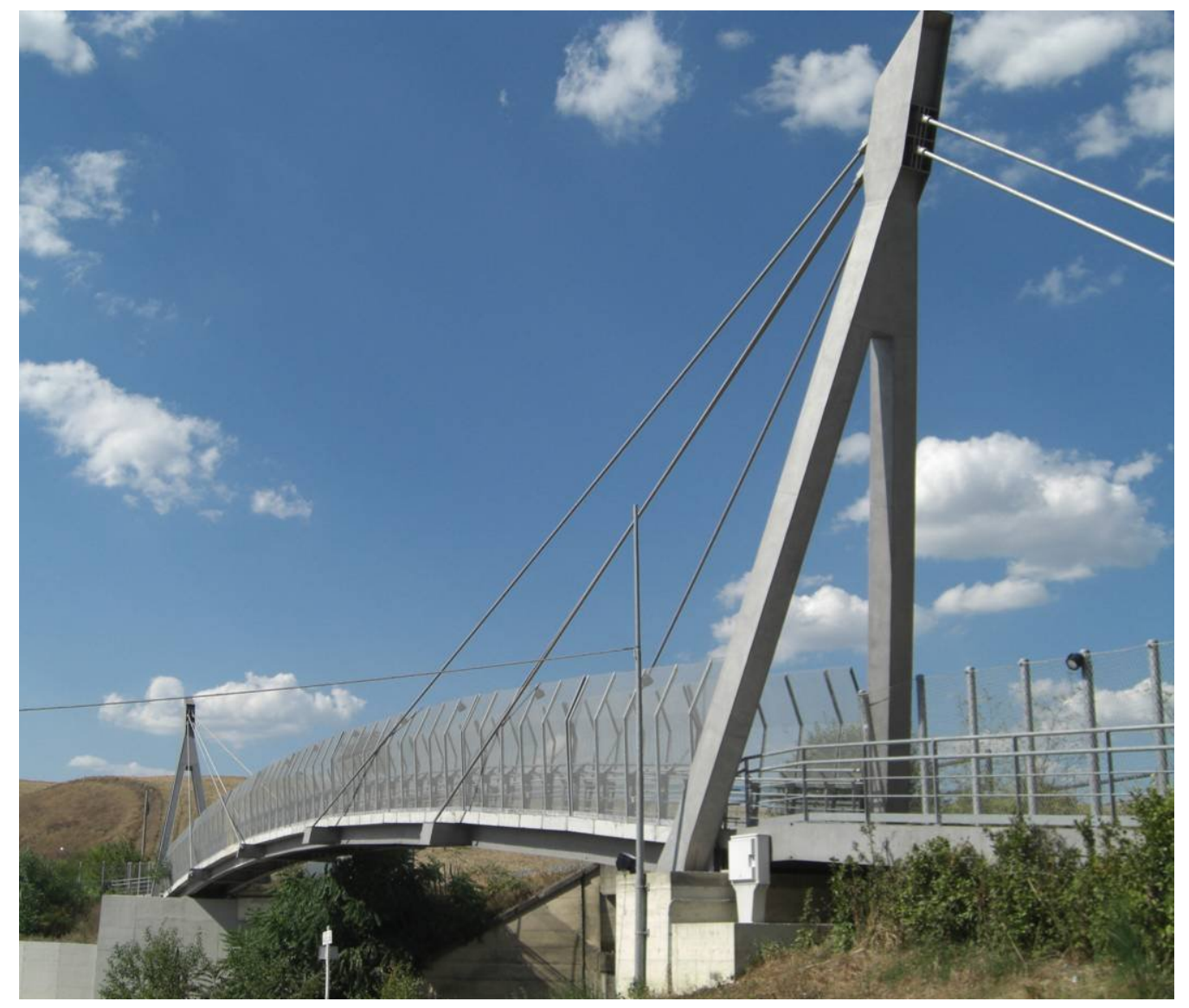

Fig. 1: Lean duplex stainless steel footbridge in Siena, Italy. 


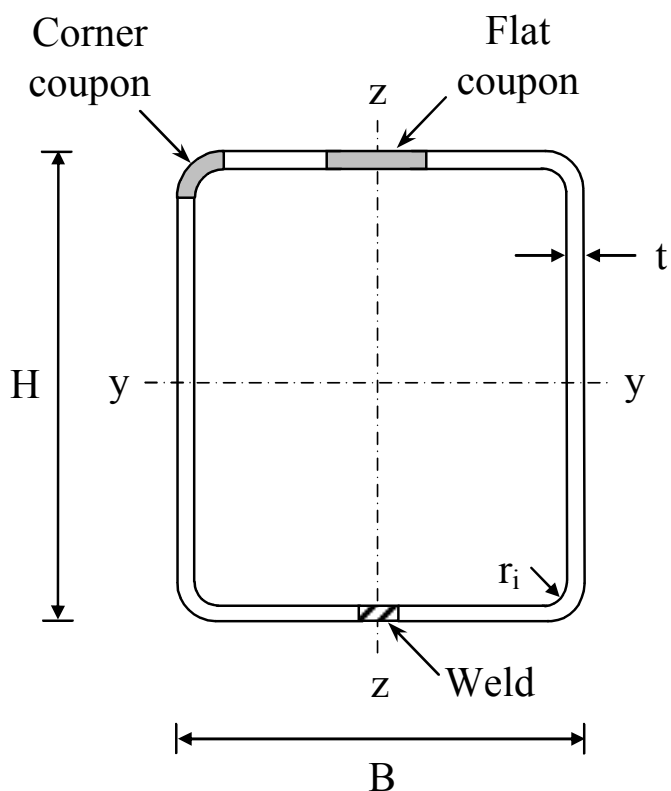

Fig. 2: Section labelling convention and location of flat and corner coupons. 


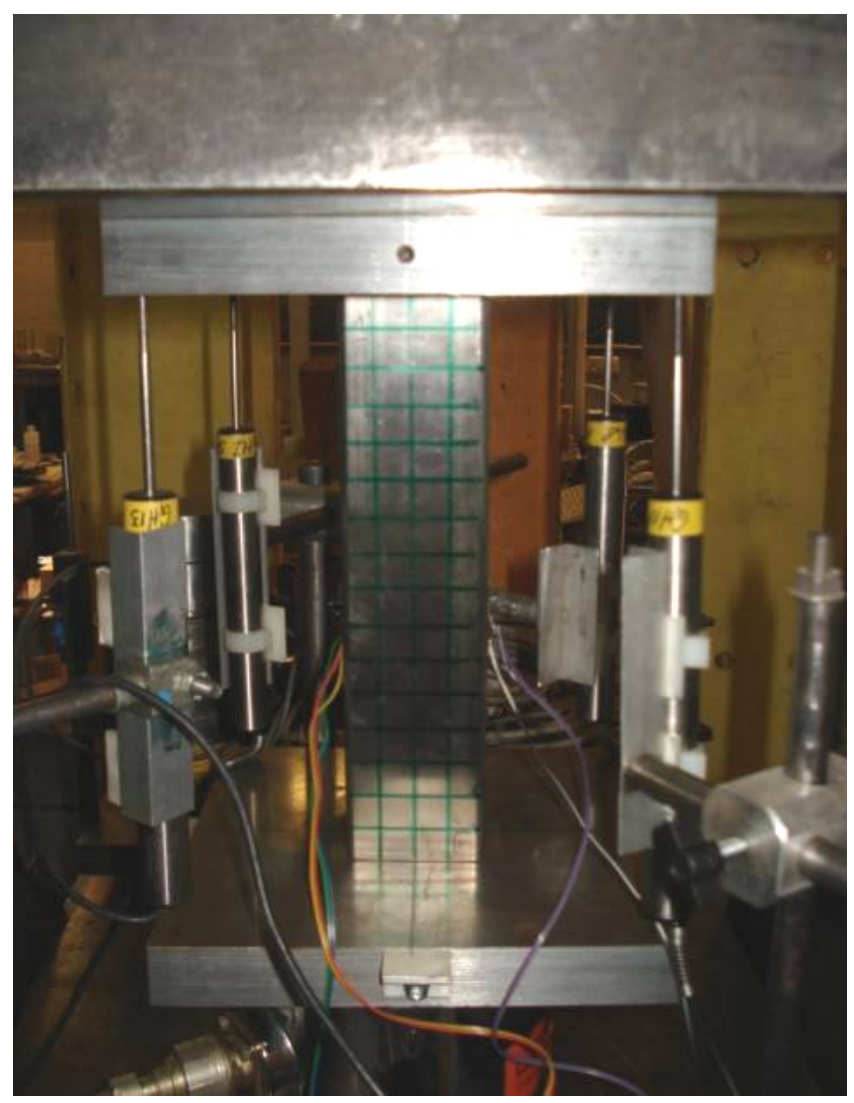

Fig. 3: Stub column testing apparatus. 


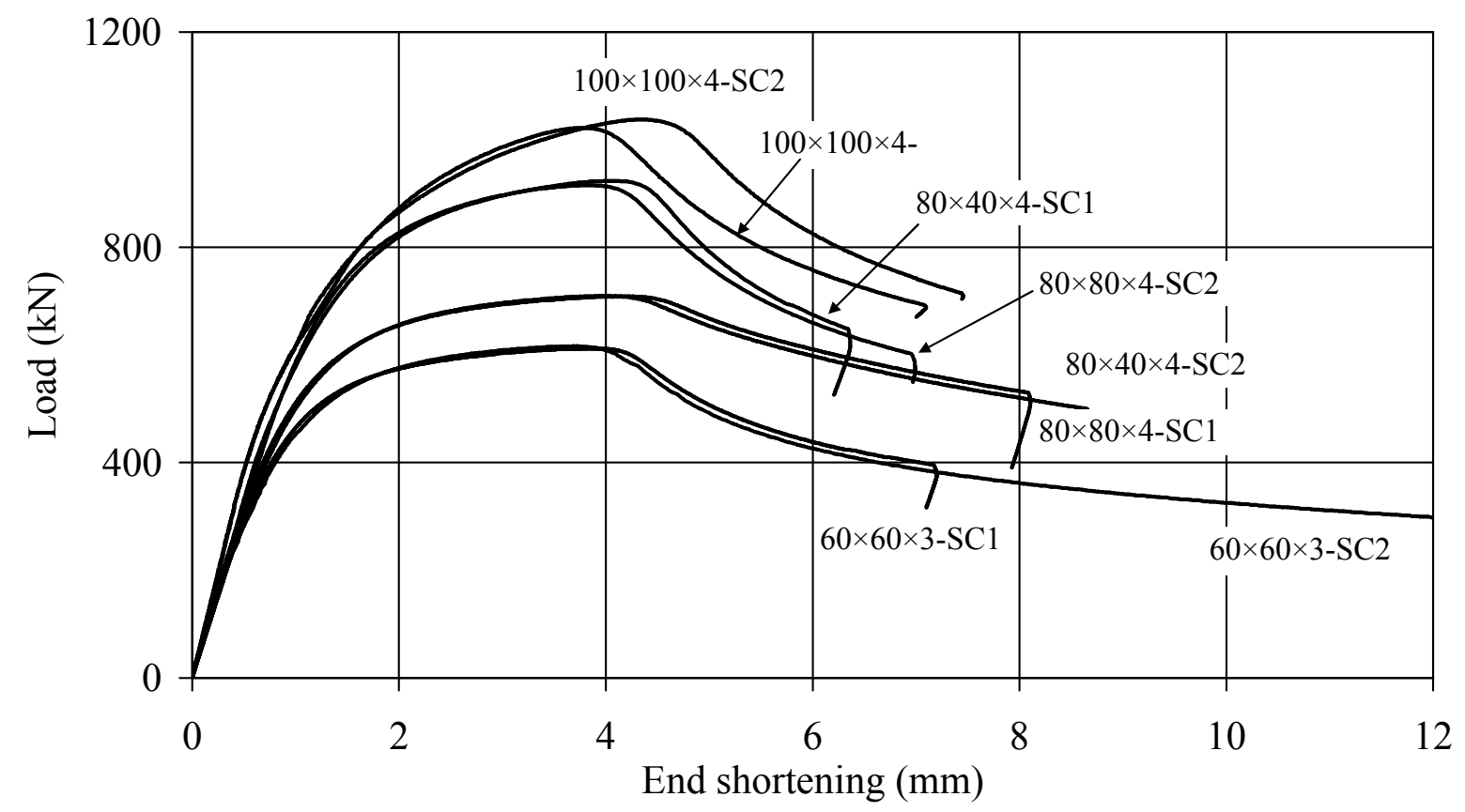

Fig. 4: Load-end shortening curves for stub columns. 

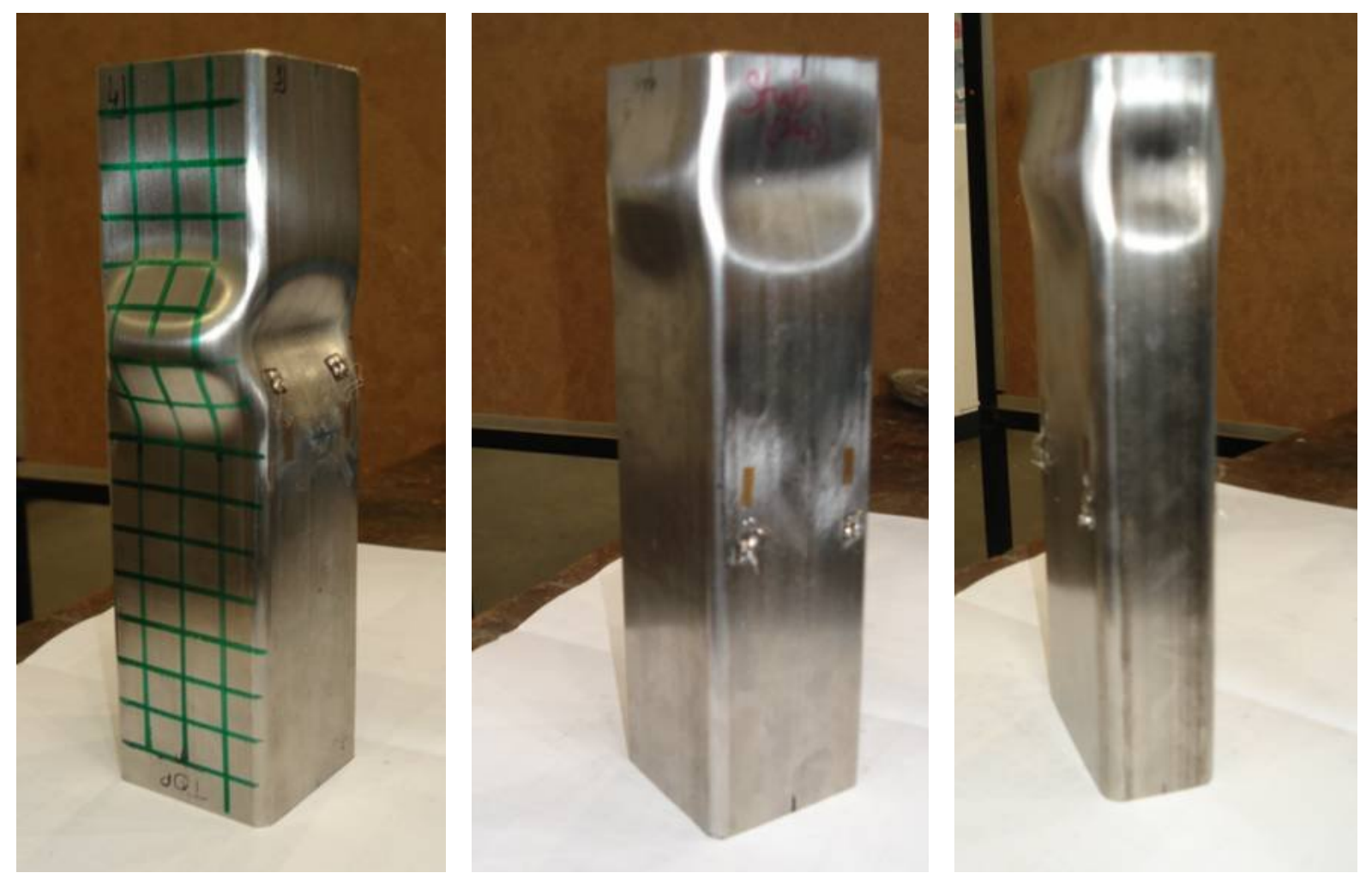

Fig. 5: Typical stub column failure modes (from left to right: $60 \times 60 \times 3-\mathrm{SC} 1,80 \times 80 \times 4-\mathrm{SC} 1$, $80 \times 40 \times 4-\mathrm{SC} 1)$. 


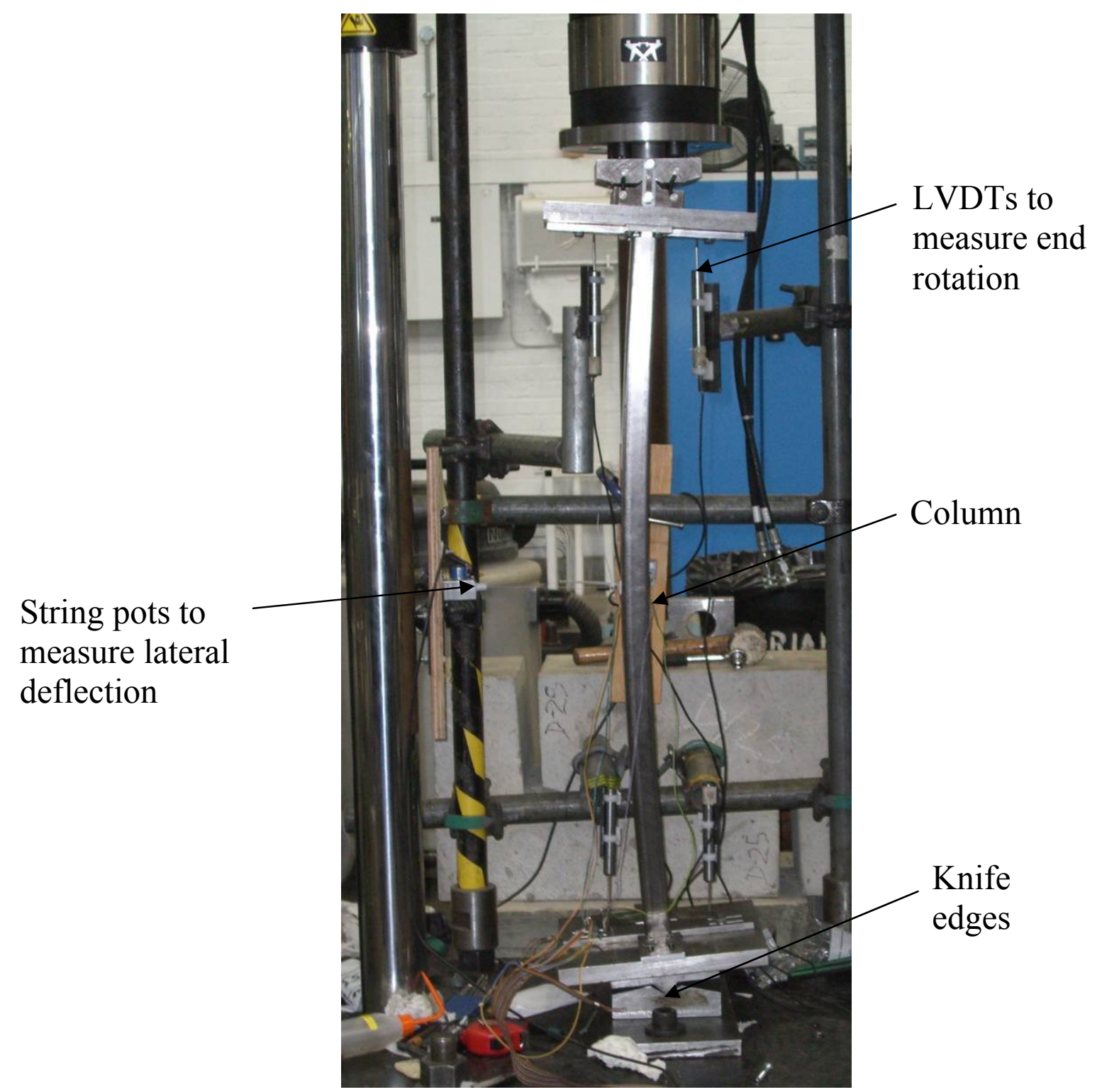

Fig. 6: Test setup for flexural buckling tests. 


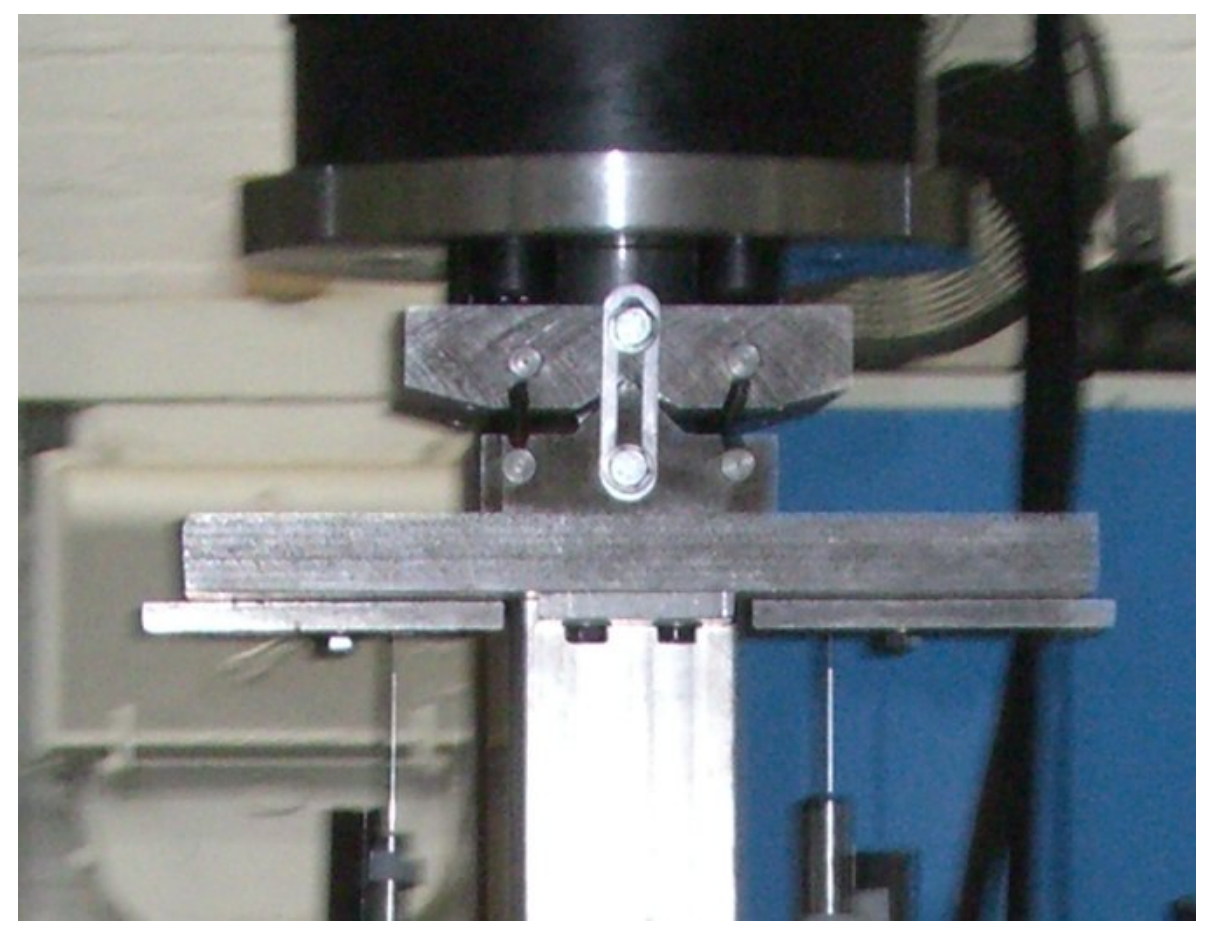

Fig. 7: Knife edge detail. 


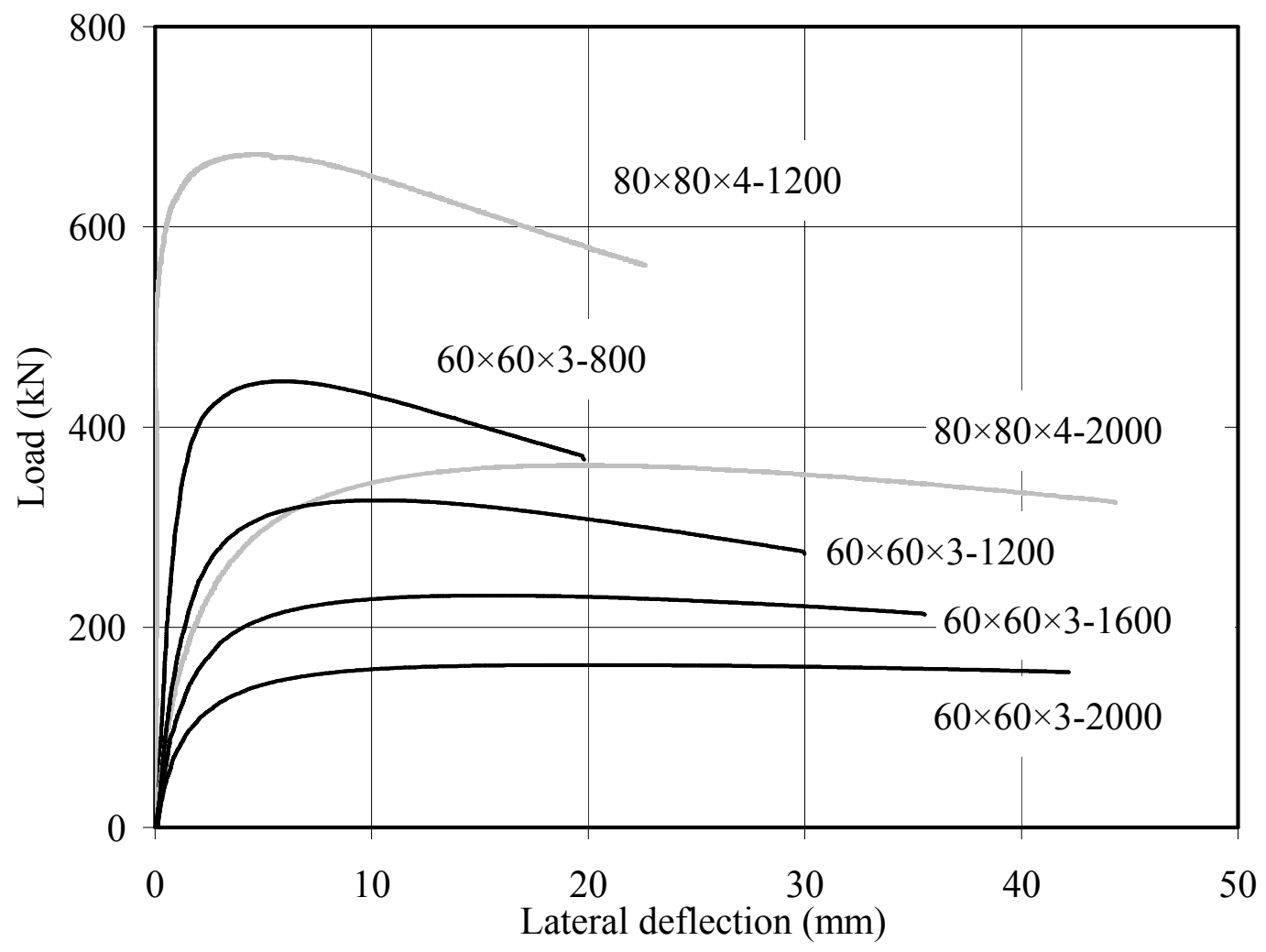

Fig. 8: Load-lateral displacement curves for SHS columns. 


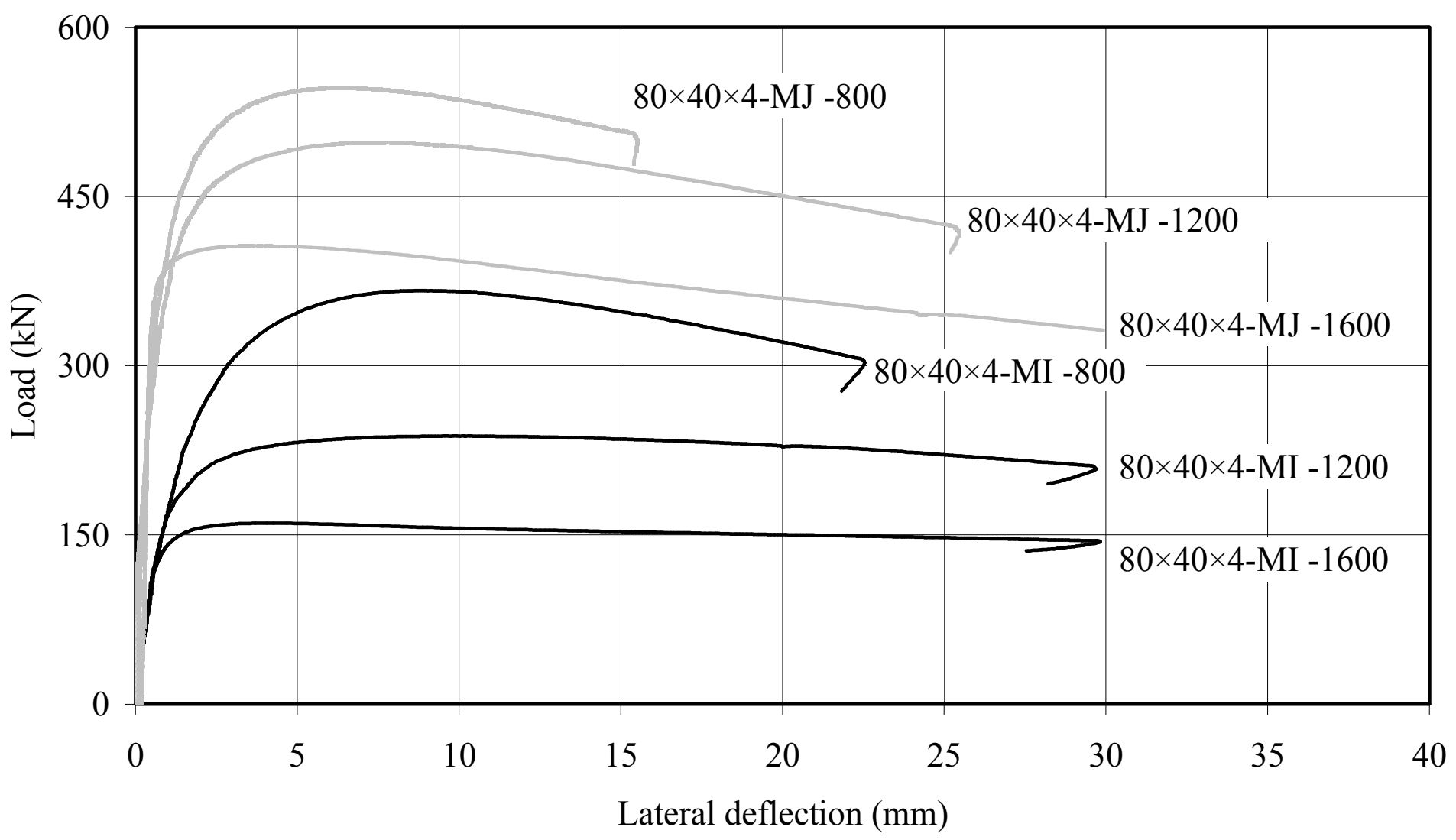

Fig. 9: Load-lateral displacement curves for RHS columns. 


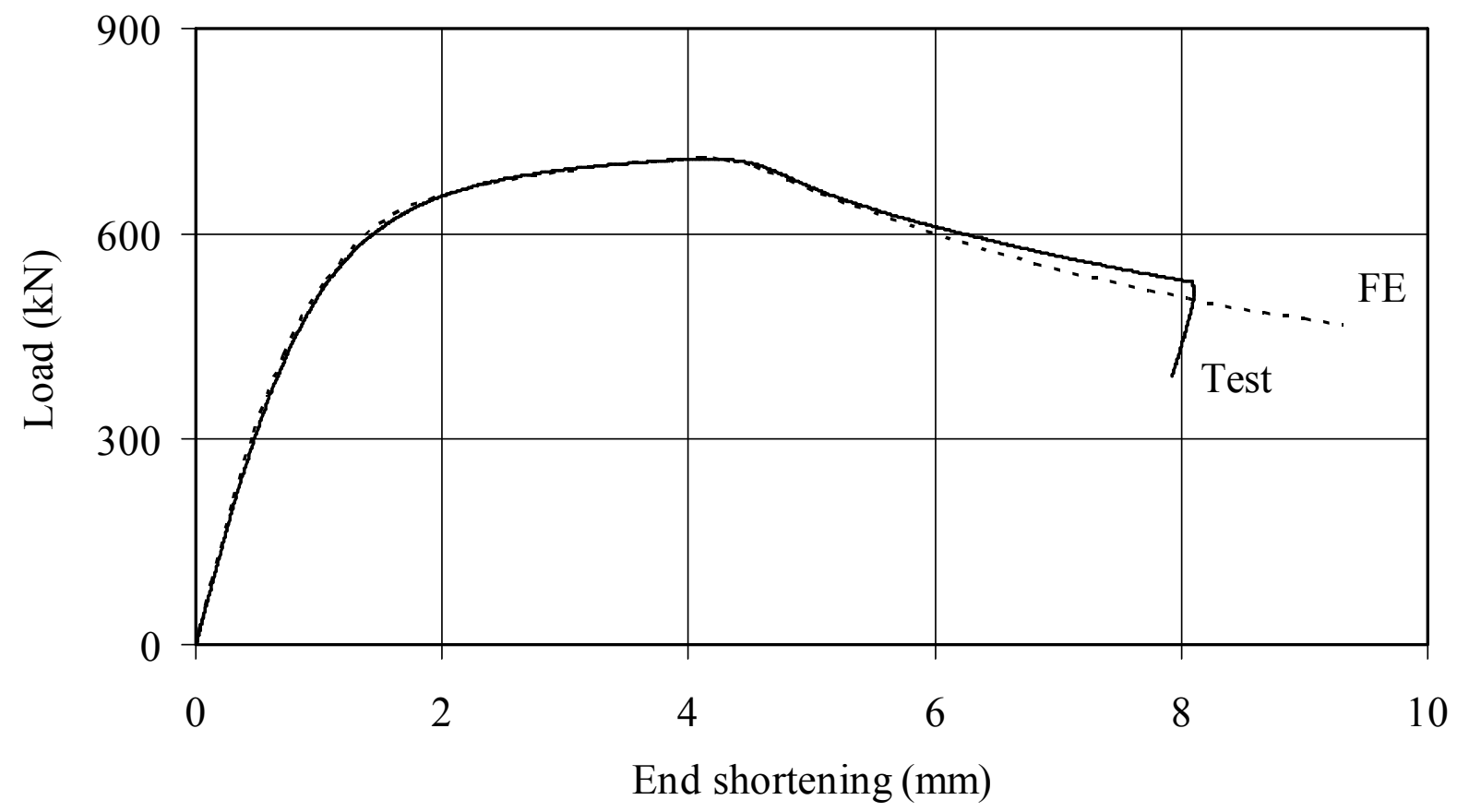

Fig. 10: Experimental and numerical load-end shortening curves for $80 \times 40 \times 4-\mathrm{SC} 2$. 


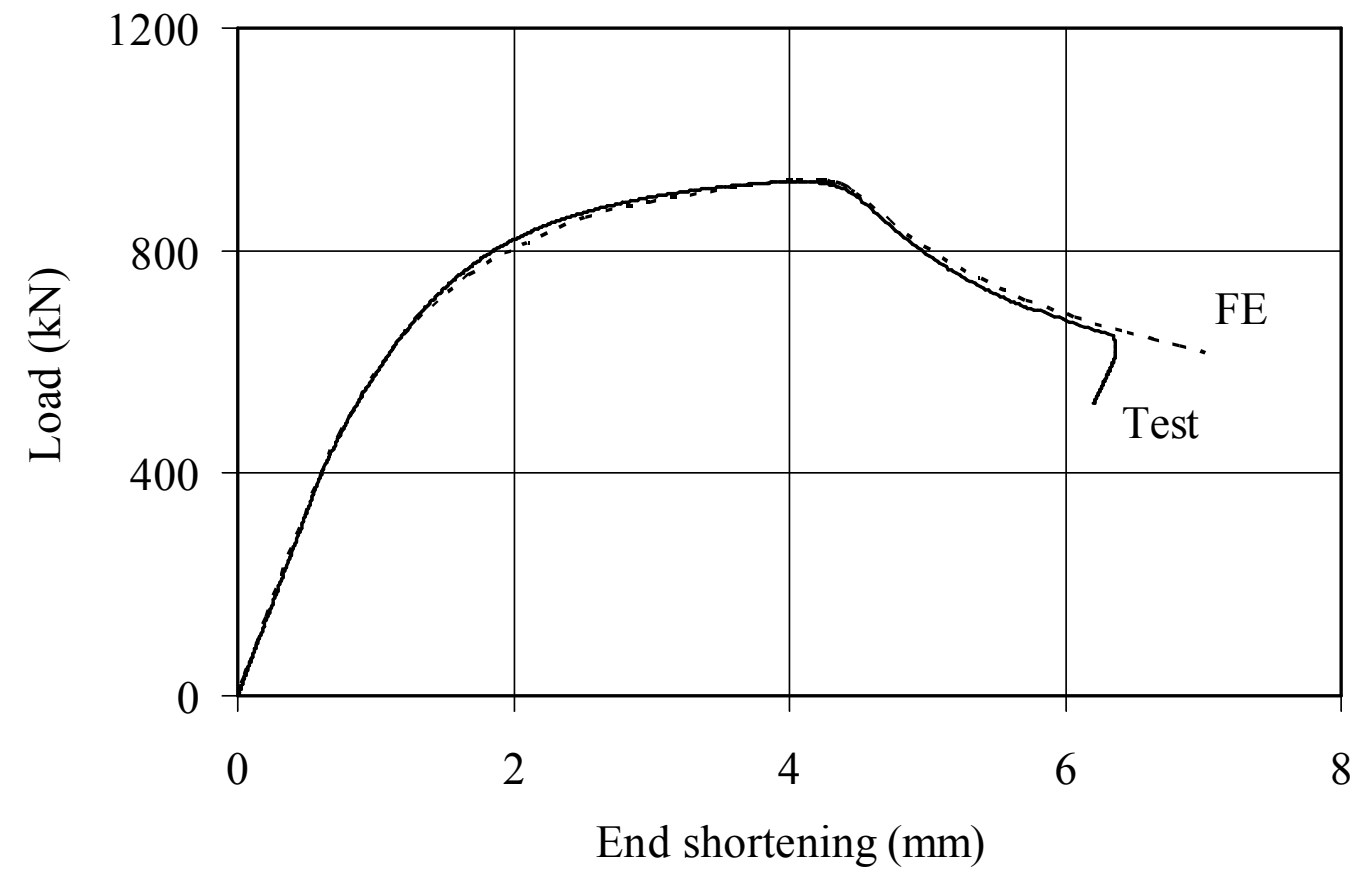

Fig. 11: Experimental and numerical load-end shortening curves for $80 \times 80 \times 4-\mathrm{SC} 2$. 

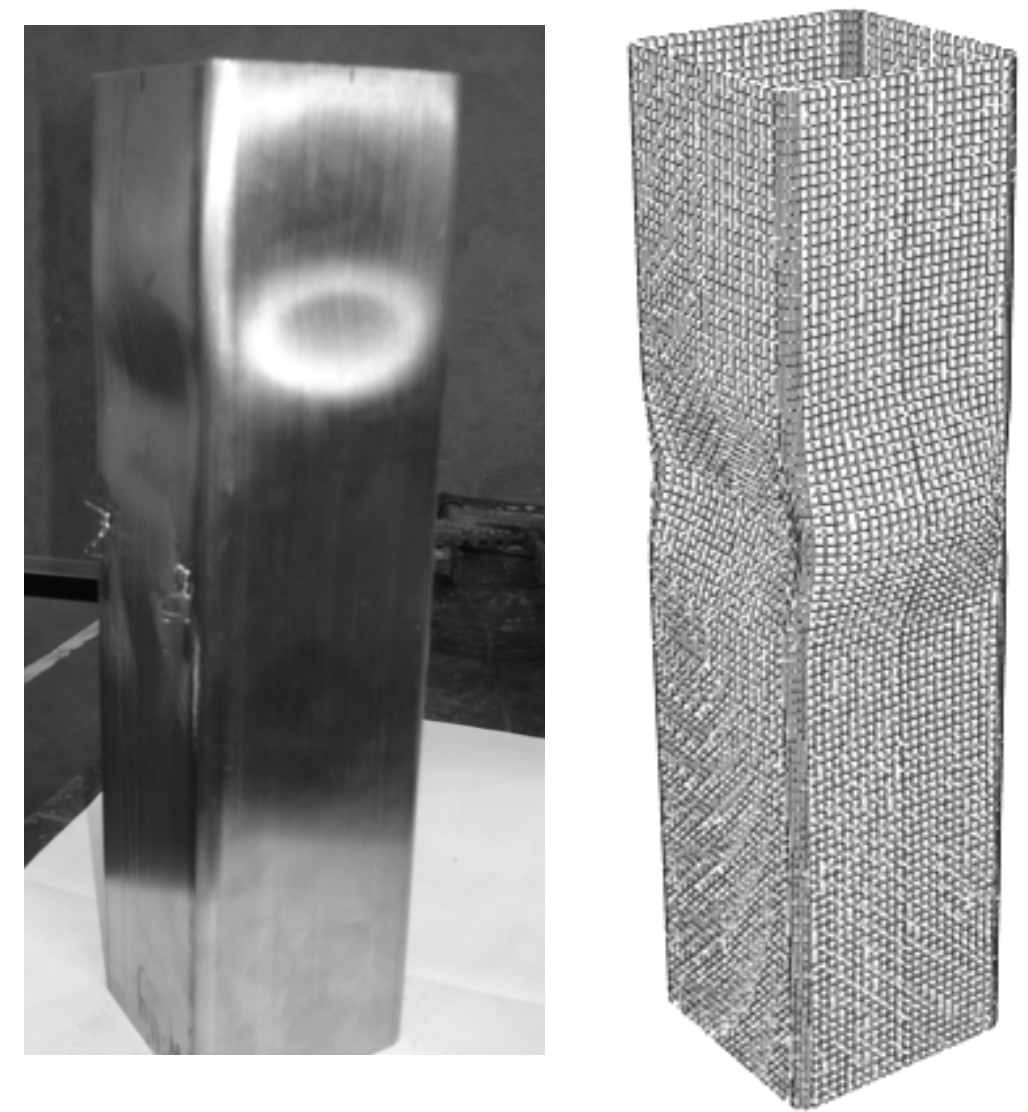

Fig. 12: Experimental and FE failure modes for SHS $80 \times 80 \times 4-\mathrm{SC} 2$. 


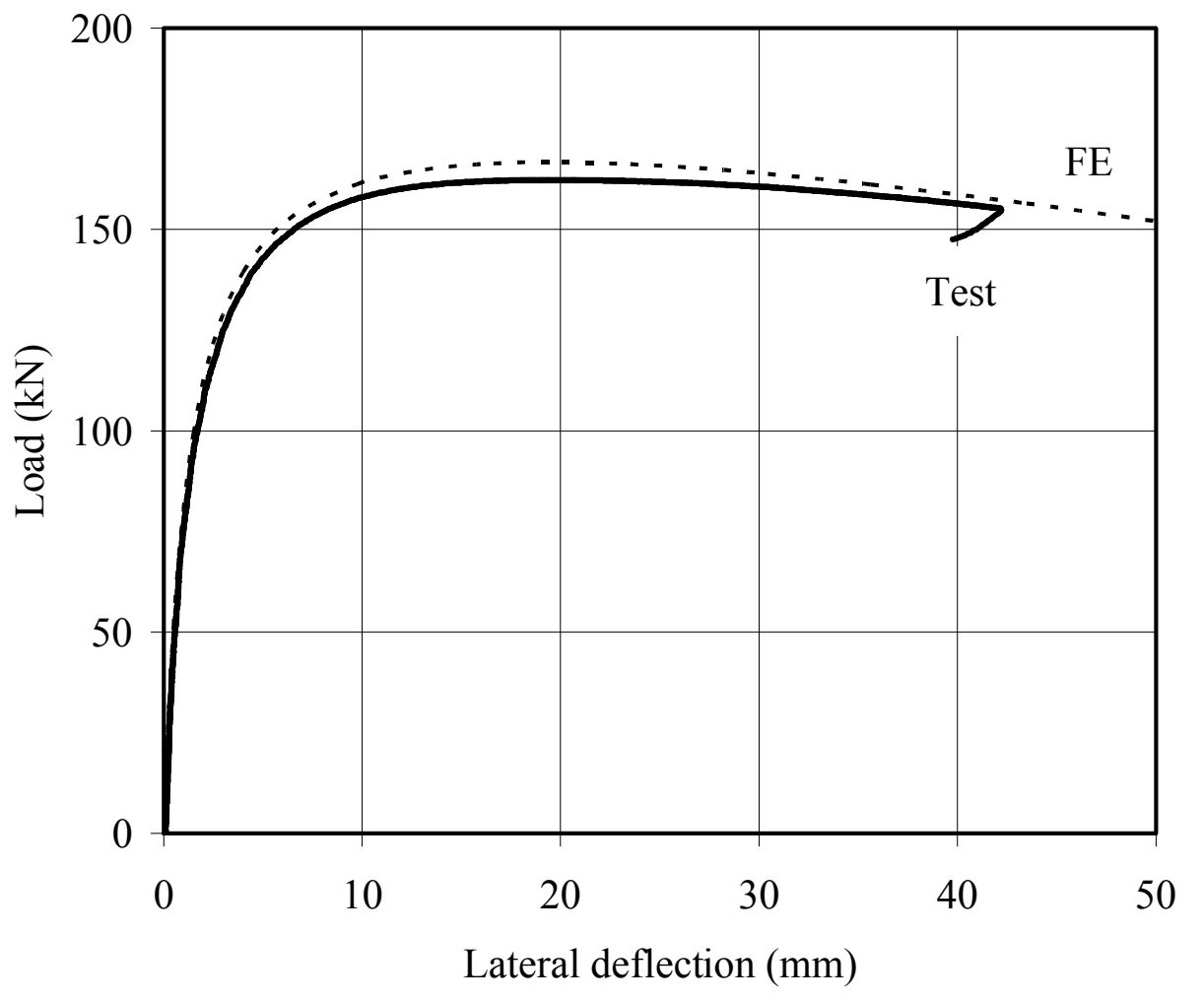

Fig. 13: Experimental and numerical load-lateral displacement cures for SHS60×60×3$\mathrm{L}=2000 \mathrm{~mm}$ column. 


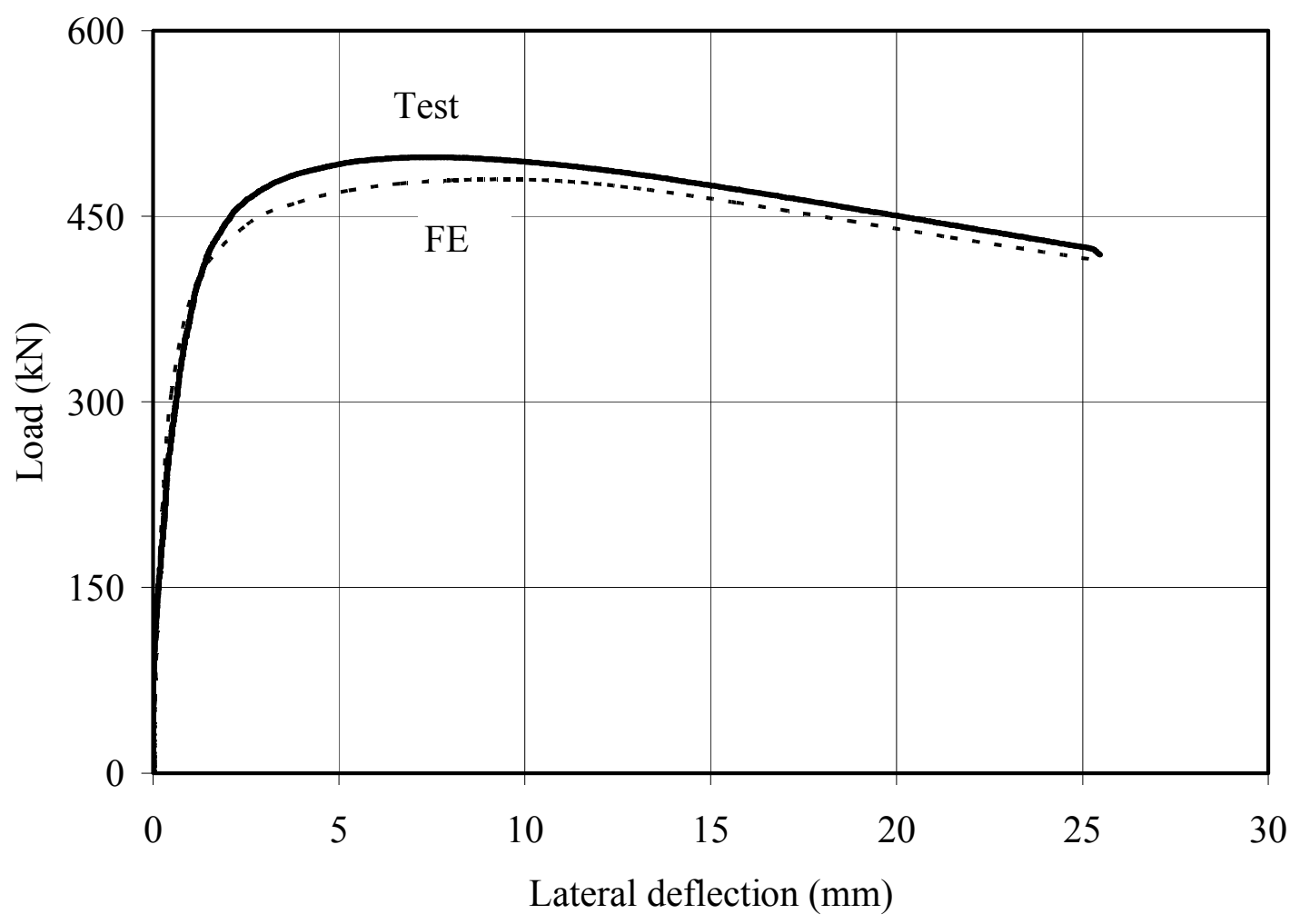

Fig. 14: Experimental and numerical load-lateral displacement cures for $80 \times 80 \times 4-\mathrm{MJ}-$ $\mathrm{L}=1200$ mm column. 


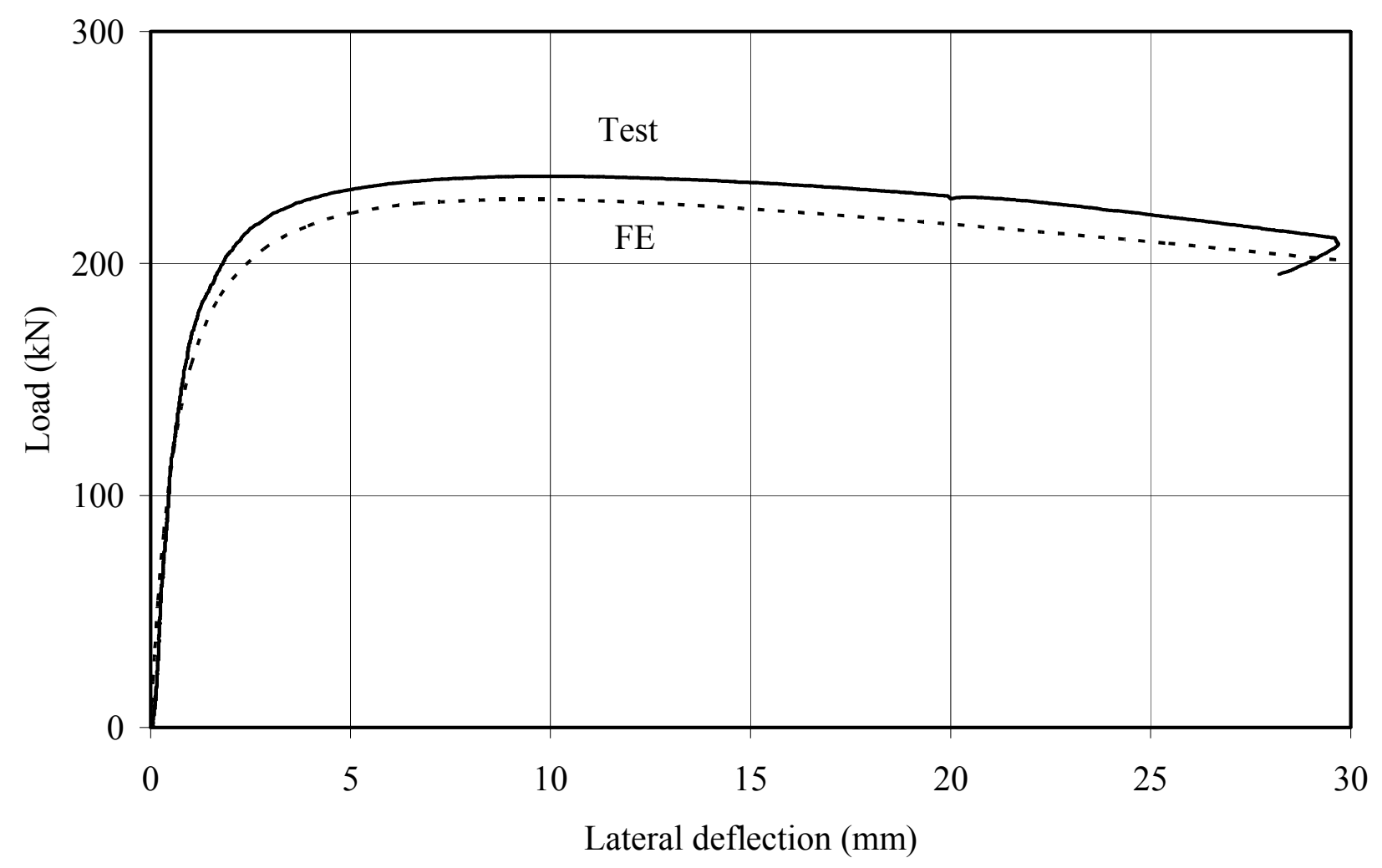

Fig. 15: Experimental and numerical load-lateral displacement cures for $80 \times 80 \times 4-\mathrm{MI}-$ $\mathrm{L}=1200 \mathrm{~mm}$ column. 

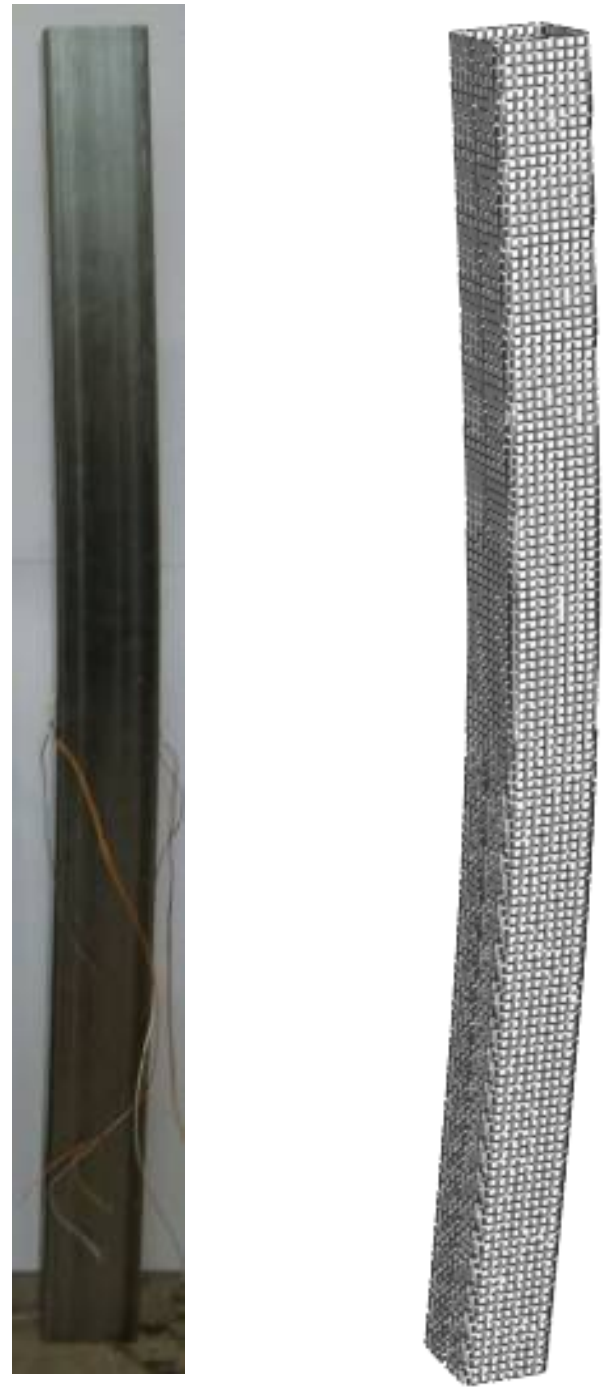

Fig. 16: Experimental and FE failure modes for SHS $80 \times 80 \times 4-\mathrm{L}=1600 \mathrm{~mm}$ column. 


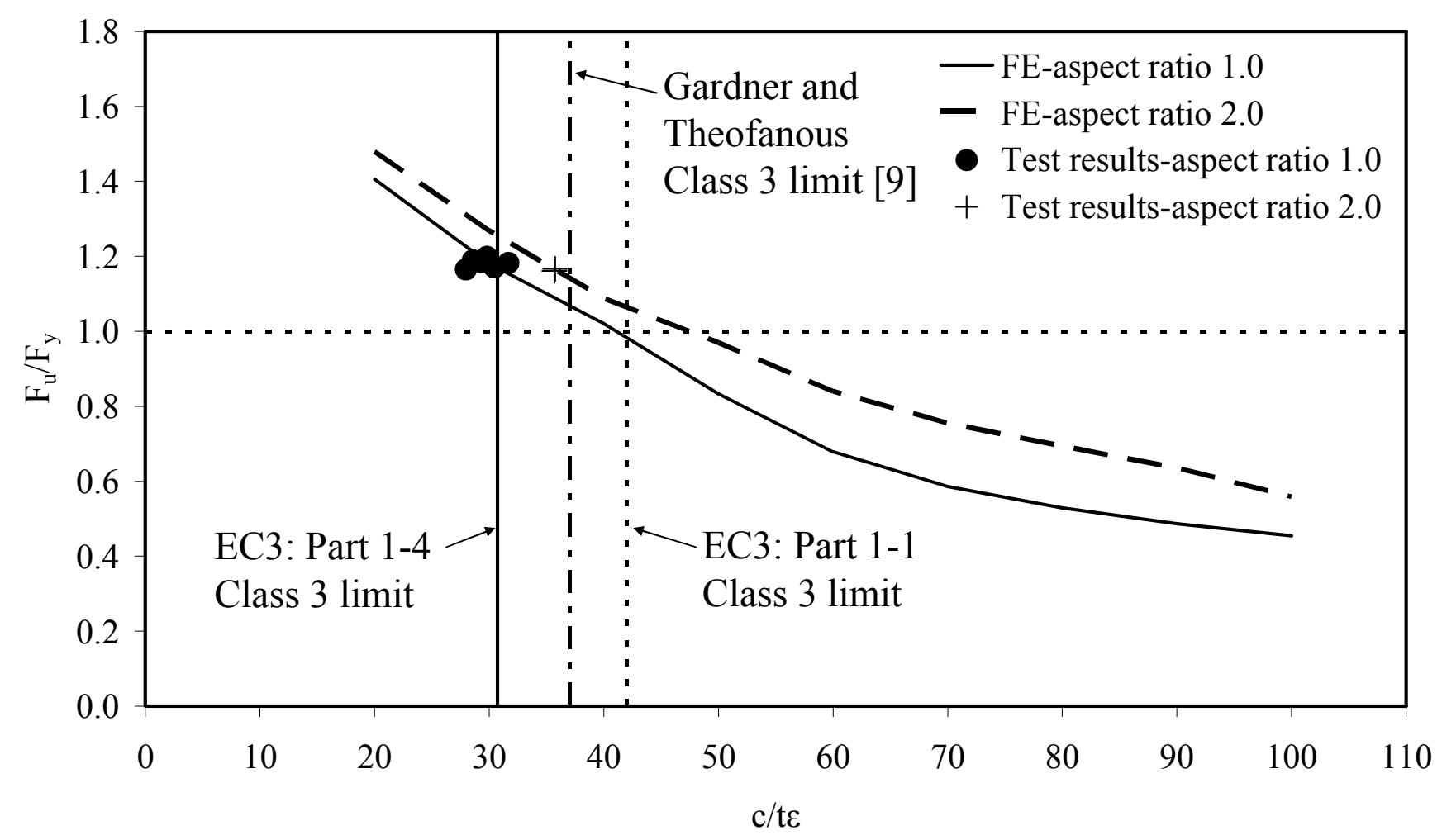

Fig. 17: Current and proposed Class 3 slenderness limit for internal elements in compression. 


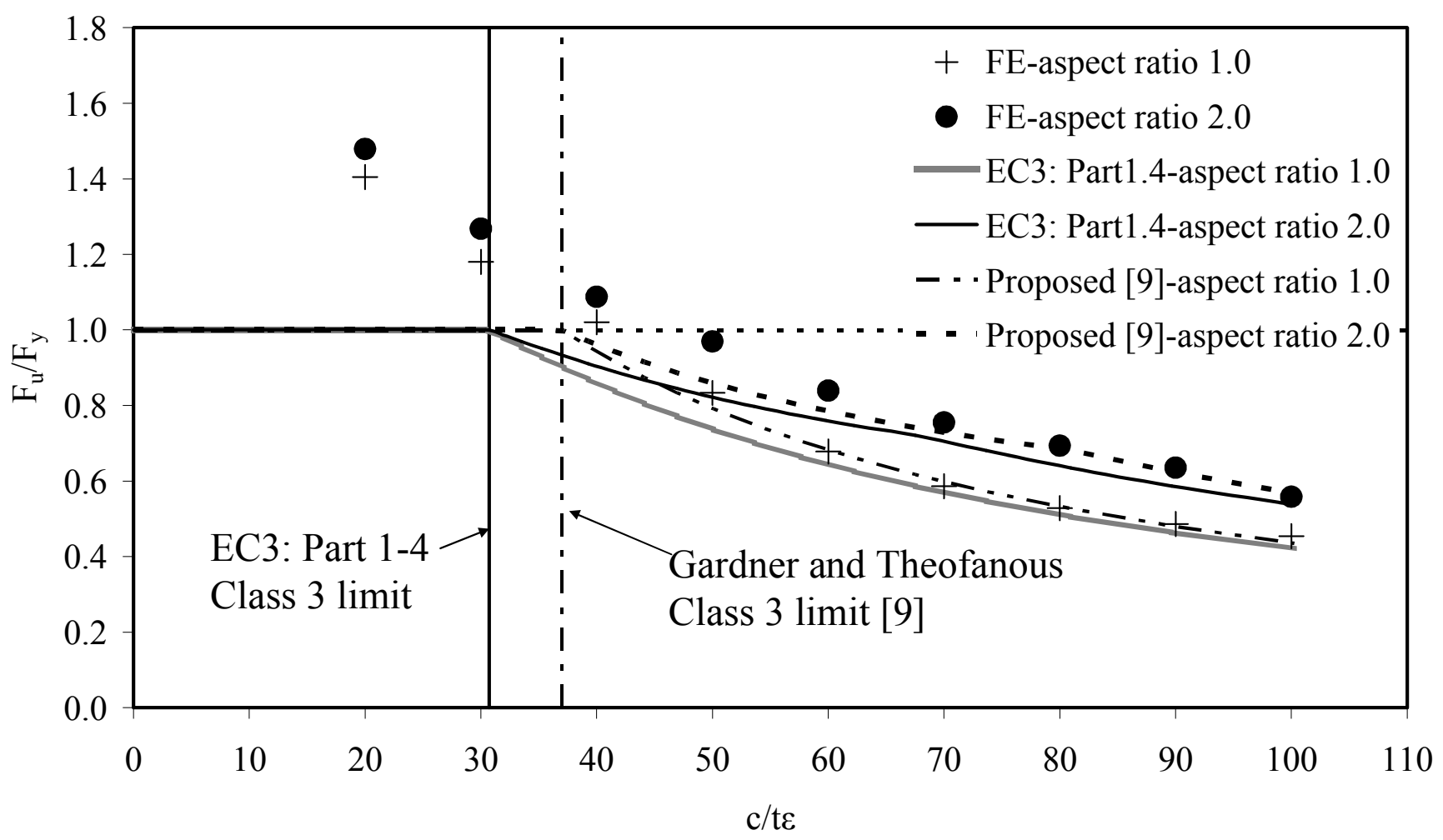

Fig. 18: Assessment of EC3: Part 1.4 and proposed effective width formulae for internal elements. 


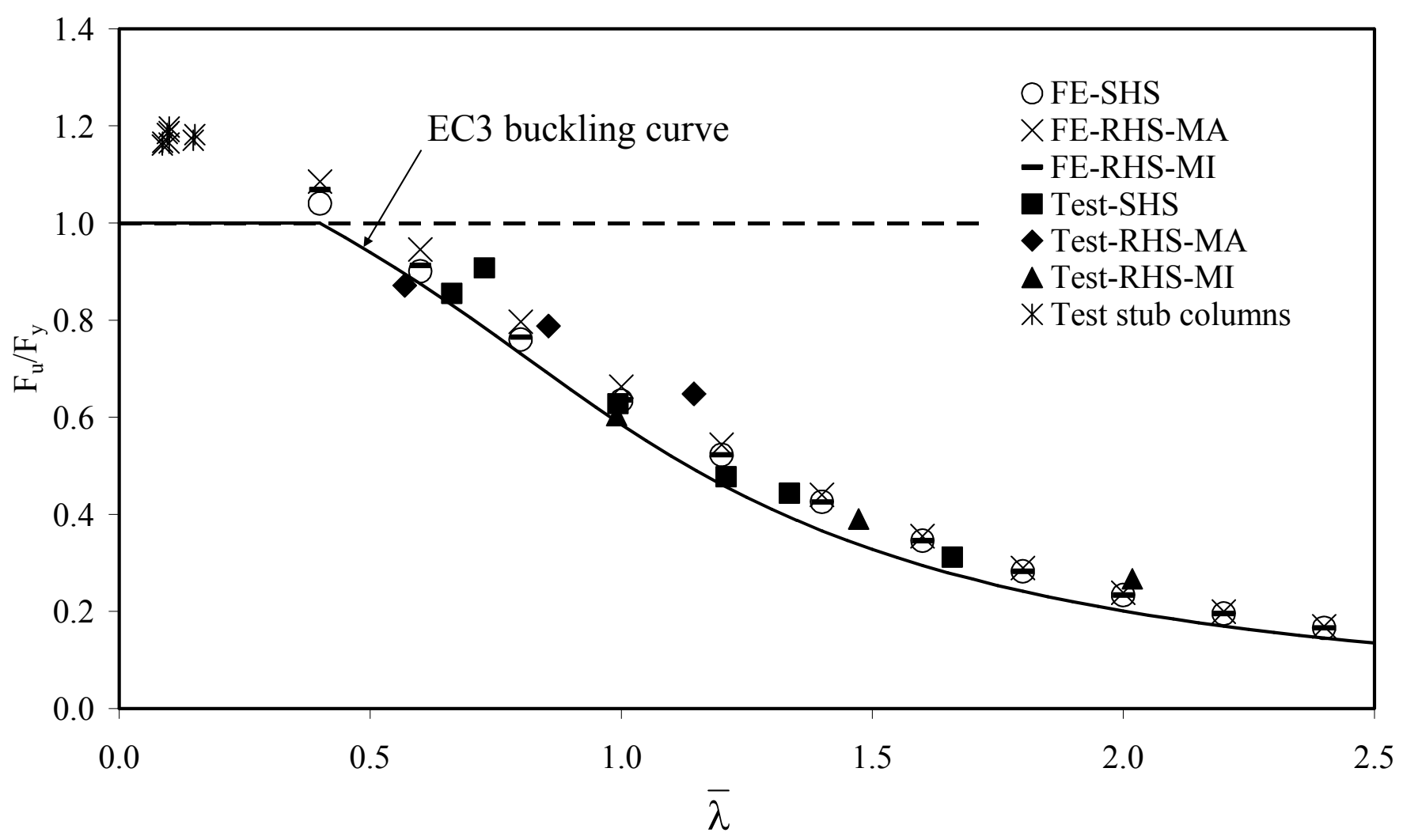

Fig. 19: Normalised test and FE column results and assessment of EC3 buckling curve. 


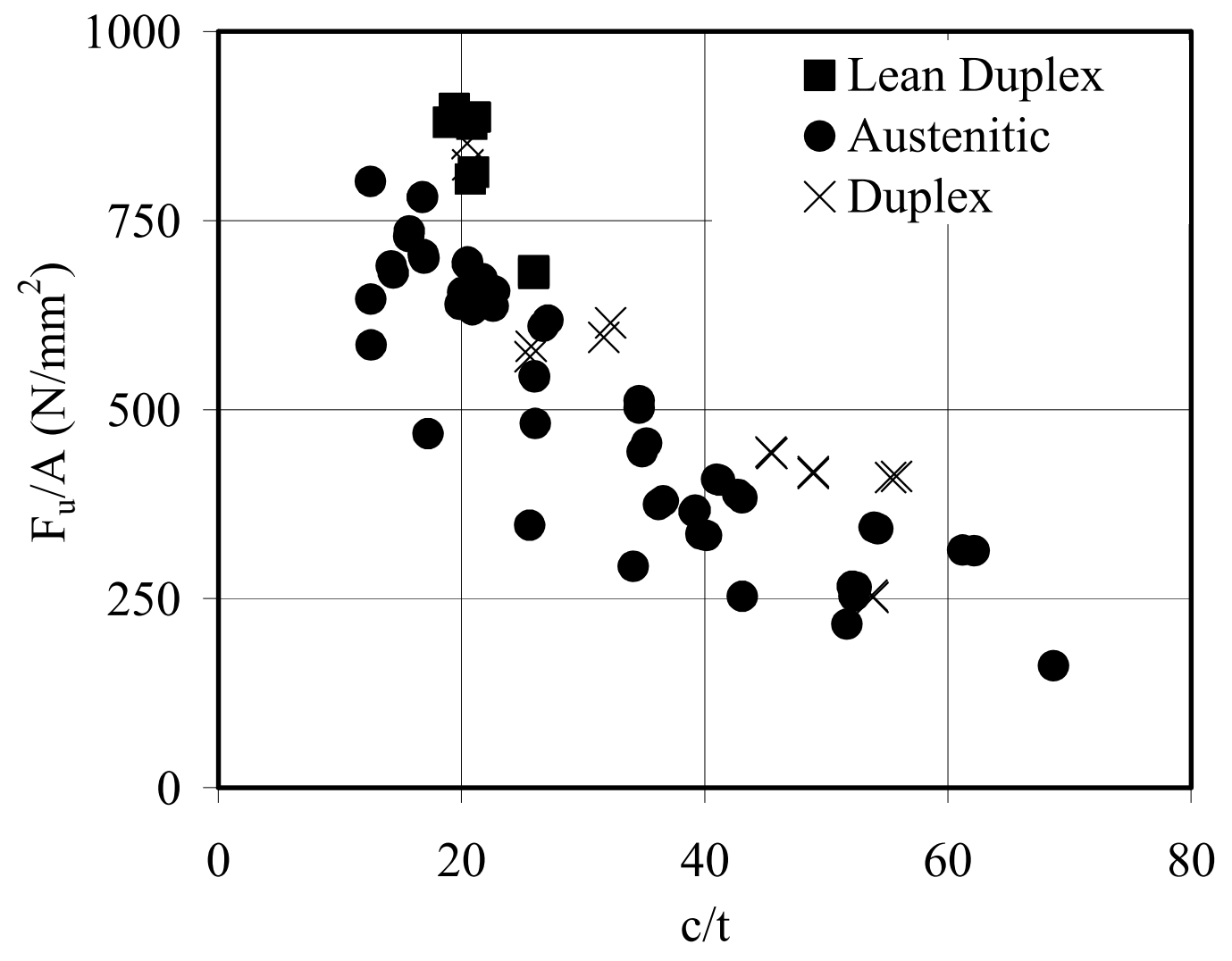

Fig. 20: Performance of stub columns of various stainless steel grades. 


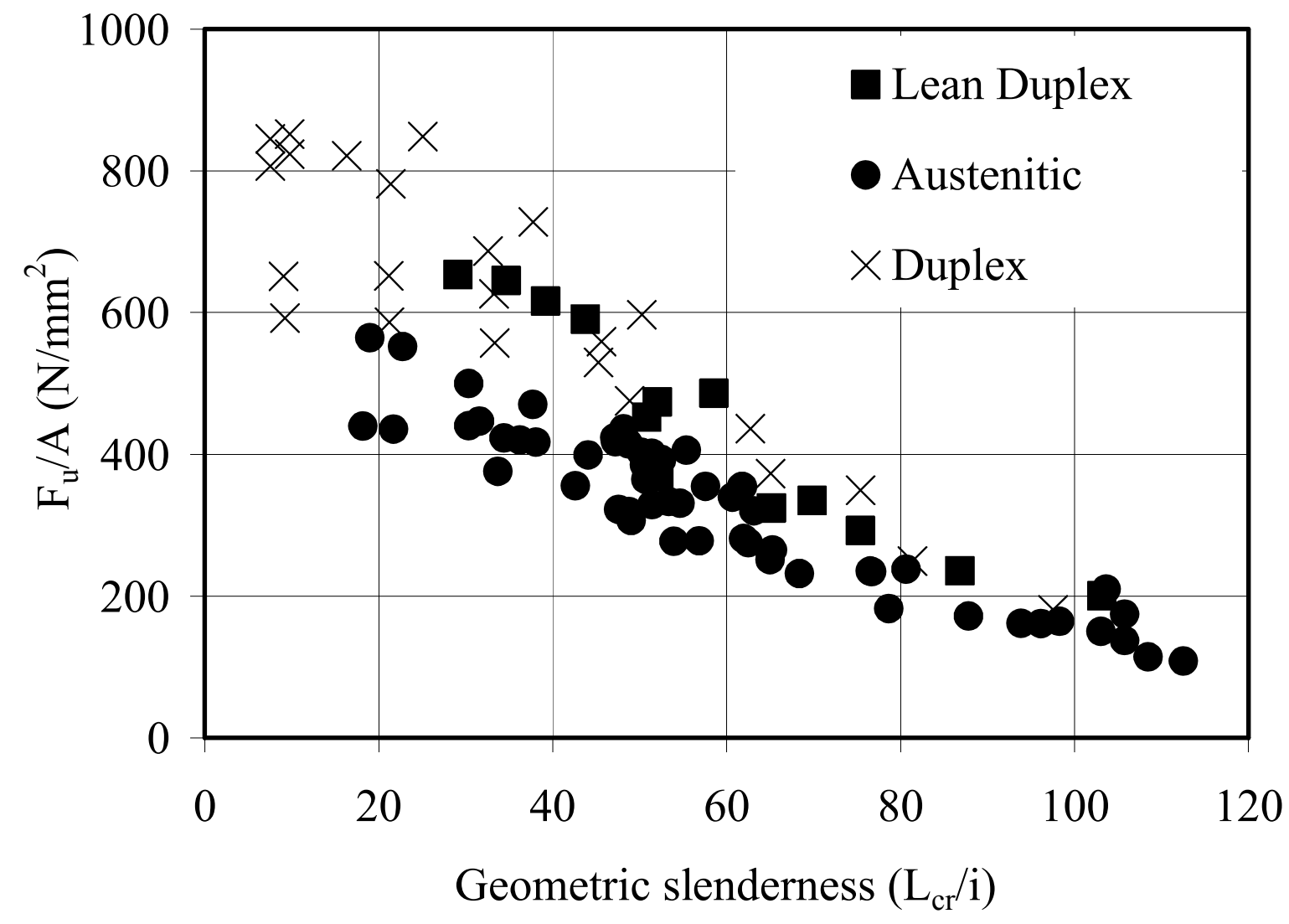

Fig. 21: Performance of columns of various stainless steel grades. 